\title{
Exportación de metales en pasta por la Costa Occidental mexicana y la creación de la Casa de Moneda de Culiacán, $1825-1870$
}

\section{Exportation of uncoined metals through the Mexican West Coast and the creation of the Culiacan Mint, 1825-1870}

\author{
Omar Velasco ${ }^{1,} *$ iD 0000-0002-7077-6838 \\ Ma. Eugenia Romero ${ }^{1}$ id 0000-0003-1238-2088 \\ ${ }^{1}$ Universidad Nacional Autónoma de México, Ciudad de México, México. \\ * Correspondencia: veho.9933@gmail.com
}

Resumen. La dinámica comercial de la Costa Occidental mexicana sirve como escenario para mostrar cómo, ante la ausencia de una ceca, fue posible mantener la extracción legal de metales sin amonedar a través de puertos como Mazatlán. La apertura de la Casa de Moneda de Culiacán en 1846 intentó poner fin a esta situación. No obstante, el gobierno estatal continuó otorgando permisos de exportación en coyunturas políticas particulares. En este artículo se analiza el conflicto generado por la coexistencia de los arrendamientos de las casas de moneda y de los permisos de la exportación de metales en pasta.

Palabras clave: comercio; casa de moneda; exportación; metales en pasta; Sinaloa.

Abstract. The commercial dynamic of Mexican West Coast exposes how it was possible to maintain the legal extraction of uncoined precious metals through ports like Mazatlán, despite the absence of a local Mint. The opening of Culiacan Mint in 1846 tried to end that practice. However, the local government continued

CÓMO CITAR: Velasco, O. y Romero, M. E. (2020). Exportación de metales en pasta por la Costa Occidental mexicana y la creación de la Casa de Moneda de Culiacán, 1825-1870. América Latina en la Historia Económica, 27(3), e1035. DOI: 10.18232/alhe.1035 
issuing uncoined silver exportation permits, which confronted the minting lessee with the federal government. This paper shows some problems generated by simultaneous existence of two important mexican regulations on monetary economy in 19th century: the leasing of various minting houses in the country and silver bullion exportations policy.

Key words: trade; mint; minting house; exports; bullion; Sinaloa.

JEL: N16; N46; N96.

Recibido: 08 de noviembre de 2018.

Aceptado: 08 de mayo de 2019.

Publicado: 15 de julio de 2020.

Organismo patrocinador: Programa de Becas Posdoctorales, Dirección General de Asuntos del Personal Académico, Universidad Nacional Autónoma de México.

\section{INTRODUCCIÓN}

El comercio por el Pacífico tuvo como referente al puerto de Acapulco durante gran parte de la época novohispana. El galeón de Manila recorrió una ruta que conectó al territorio americano con el exterior de oriente a poniente. Desde Europa hacia Veracruz, y por tierra hasta Acapulco, fue posible unir el espacio marítimo del Atlántico con el Pacífico. Otra vía existente fue la que conectaba la metrópoli con Portobelo a través del Callao. Esta última tuvo vinculación comercial con Acapulco y dio origen a otro nodo comercial que unía el virreinato del Perú con Asia. Sin embargo, este mapa de conectividad habría de cambiar a partir de la segunda mitad del siglo XviII. Según Bonialian y Hausberger (2018, pp. 204-208), tras la implementación en 1739 de los navios de registro, quedó bajo control de la corona española el comercio por el Atlántico y el Pacífico sudamericano a través del paso por Cabo de Hornos. Esta política tenía el objetivo de reforzar los intereses comerciales ibéricos en el espacio marítimo del Mar del Sur que se había volcado hacia China, así como reducir el comercio ilegal entre Manila, Acapulco y Perú.

Para finales del siglo XVIII y principios del XIX, en el marco de los preludios de la revolución industrial y de las guerras de independencia hispanoamericanas, estas rutas comerciales empezaron a ser intervenidas por el comercio europeo, británico y angloamericano (Bonialian y Hausberger, 2018, p. 209). El levantamiento insurgente en la Nueva España interrumpió la ruta del camino de Tierra Adentro, fundamental para comunicarse con la parte norte del territorio, y en este contexto, Acapulco fue tomado entre 1813 y 1814. Estos y otros sucesos trastocaron el orden mercantil novohispano, por ejemplo, las necesidades bélicas en zonas como Michoacán y Guadalajara hicieron que los cauces comerciales por el Pacífico se intensificaran. Esta situación en concreto dio lugar a una triangulación entre Guaymas, San Blas y Panamá, lo que permitió la introducción de mercancías de origen extranjero llevadas a Portobelo desde Jamaica en naves británicas (Sánchez, 2016, p. 52). Sin duda, la guerra intensificó el dinamismo comercial de la Costa Occidental mexicana.

Entre 1810 y 1814 llegaron al puerto de San Blas veinticinco buques, de los cuales once provenían de Panamá, todos cargados con mercancías extranjeras; el número aumentó a cincuenta y tres en 1816, año en que el puerto recibió un permiso para comerciar con aquella región centroamericana (Ibarra, 1998, p. 375). Los mercaderes de la ciudad de México denunciaron este suceso haciendo énfasis en la salida del oro y la plata producidos en los minerales cercanos a aquel puerto. Según estos comerciantes, el valor del metal extraído por aquellas latitudes era de 20000000 de 
pesos, una cifra sobredimensionada pero que daba cuenta de la dinámica que se había configurado (Sánchez, 2016, p. 53). Este reclamo estaba relacionado también con el impacto que tuvo la guerra de independencia en la acuñación de metales.

Entre 1535 y 1810 la Casa de Moneda de la Ciudad de México fue la única productora de cuños en Nueva España. Con el estallido de la guerra, aumentaron los riesgos del camino de la plata a la capital novohispana, por lo que las autoridades permitieron la apertura de establecimientos de acuñación provisional. A partir de entonces las casas de moneda regionales generaron intereses entre las elites locales y en los circuitos comerciales ligados a la minería. En 1815, con la insurgencia debilitada, se ordenó el cierre de todas las casas de moneda abiertas durante la guerra, lo que provocó la defensa de éstas por parte de corporaciones y comerciantes regionales. Fue en Zacatecas y Guadalajara donde se dieron los casos más relevantes de un proceso que buscó mantener en funcionamiento sus respectivas cecas, lo que consolidó su reconocimiento oficial por parte de las cortes españolas en noviembre de 1820 (Matamala, 2008, p. 68).

Tras la consumación de la independencia, los gobiernos de la regencia y del imperio mexicano mantuvieron funcionando casas de moneda en Durango, Guadalajara, Zacatecas y Guanajuato, a las que se les ordenó usar matrices y troqueles enviados desde la capital. Esto significó el reconocimiento de la descentralización de la acuñación por parte del nuevo gobierno nacional (Dublán y Lozano, 1876, t. I, pp. 661-662; Matamala, 2008, p. 68). La llegada del esquema federal en 1824 impulsó el interés por abrir cecas en varios estados, particularmente en aquellos que contaban con recursos mineros. Esto se vio favorecido con la repartición de rentas que ocurrió el 4 de agosto de ese mismo año y dejó en manos de las entidades federativas los ingresos generados por las casas de moneda 11 Bajo esta circunstancia, algunos gobiernos estatales buscaron financiar la apertura o rehabilitación de sus establecimientos de acuñación a través de contratos de arrendamiento. Hubo otros casos en donde la ceca fue operada y financiada por el gobierno estatal, tal como ocurrió en Zacatecas (Matamala, 1996, 1998; Martínez, 2012). 22 Esto dio pie a un escenario heterogéneo a nivel regional en donde la forma en que fueron administradas las casas de moneda dependió de las condiciones de los erarios estatales, la dinámica de la minería, los intereses políticos regionales y las expectativas de inversión, sobre todo del capital británico.

La historiografía que aborda el análisis de las casas de moneda y sus arrendamientos sostiene que esta práctica fue muestra de los serios problemas que tuvieron las finanzas públicas durante los primeros años de vida independiente. Se trataba de acuerdos en donde, a cambio de préstamos, el gobierno cedió a empresas privadas dos facultades: acuñar y recaudar los derechos de amonedación. De allí que sean considerados como evidencia de la debilidad del Estado mexicano (Ortiz, 1998, p. 144; Velasco, 1994, p. 161). Este trabajo se enfoca en mostrar cómo los contratos de arrendamiento también sirvieron para delimitar las potestades fiscales del gobierno mexicano frente a las de los estados, lo cual permite comprender mejor el proceso de construcción de la hacienda pública nacional durante el siglo XIx.

\footnotetext{
${ }^{1}$ Una vez que fueron definidas las rentas de la federación en 1824, el artículo 11 del decreto obligó que "Las rentas que no están comprendidas en los artículos anteriores pertenecen a los estados” (Dublán y Lozano, 1876, t. I, p. 710). Dentro de las rentas no definidas estaban las de las casas de moneda, una situación que generó conflictos entre las distintas soberanías fiscales.

${ }^{2} \mathrm{El}$ caso paradigmático de una casa de moneda operada por un gobierno estatal fue el de Zacatecas. Al respecto, véanse Matamala $(1996,1998)$ y Martínez (2012).
} 
El análisis de las casas de moneda, paralelo al del comercio exterior durante el siglo XIX, revela una problemática: la coexistencia de los arrendamientos y la exportación de metales sin acuñar generó fricciones entre los arrendatarios y el gobierno mexicano puesto que, en los contratos, este último se comprometió a prohibir la exportación de dichos metales. Esta situación no ha pasado desapercibida por la historiografía. Inés Herrera (1999, p. 24) sostiene que la crisis fiscal del siglo XIX tuvo una de sus expresiones más claras cuando el gobierno empezó a otorgar permisos de exportación de plata en barras a cambio del cobro de derechos y la obtención de préstamos en efectivo. Asimismo, menciona el caso de aquellos que fueron otorgados durante el gobierno de Benito Juárez a la compañía de Real del Monte y que generaron reclamos del arrendatario de la ceca de la Ciudad de México. La exigencia de una indemnización dio paso a un proceso judicial que acabó involucrando a los representantes diplomáticos estadounidenses en México, quienes abogaron en favor del contratista bajo la consigna de hacer efectivo el pago de una compensación económica (Mendizábal, 1868, pp. 27-29).

En este sentido, el presente artículo analiza un estudio de caso que permite comprender cómo la salida de plata en pasta se convirtió en uno de los dilemas de la política fiscal y comercial de los primeros gobiernos del México independiente, así como un síntoma de la necesidad de recursos por parte del erario nacional. De esta forma, la apertura de casas de moneda en los estados y las vicisitudes ligadas a ello son el punto de partida para exponer un debate gestado en 1830: el de la conveniencia o no de abrir más casas de moneda frente al primer intento del gobierno mexicano de hacer posible la exportación de metales preciosos sin acuñar.

En otro apartado esbozamos dos ejes analíticos a través de los cuales es posible comprender los acontecimientos relativos a la ceca de Culiacán: el primer eje da cuenta de la dinámica comercial de la Costa Occidental mexicana y la preponderancia de Mazatlán, puerto de salida de cantidades relevantes de metales en pasta; el segundo, consiste en un recorrido por la regulación de la exportación de metales en barras y el estado de excepción en el que estuvieron Guaymas y Mazatlán durante la primera mitad del siglo XIX, situación que hizo posible la extracción legal de plata sin acuñar por esos puertos. Aunque la puesta en marcha de la ceca de Culiacán en 1846 debía poner fin a esta situación, nuestra hipótesis es que persistió una inercia en la exportación de metales que, en conjunción con las necesidades fiscales de los gobiernos, nacional y estatal, hicieron que la plata siguiera saliendo sin ser acuñada.

Finalmente, examinamos cómo los permisos para exportar plata en pasta expedidos en septiembre de 1855 por el gobierno de Sinaloa dan cuenta de la sobreposición de atribuciones fiscales del gobierno estatal en menoscabo del nacional, situación que expone la desarticulación institucional y el caos político de la época. Esto desencadenó un conflicto entre el gobierno mexicano y el arrendatario de la Casa de Moneda de Culiacán que, en mediano plazo, terminó en la rescisión del contrato; medida que resultaba acorde con una política nacional que intentó reincorporar las casas de moneda arrendadas a la administración pública nacional.

\section{LAS CASAS DE MONEDA EN LOS ESTADOS, SUS ARRENDAMIENTOS Y LA EXPORTACIÓN DE METALES EN PASTA}

El primer arrendamiento de una ceca estatal fue en Guanajuato, este caso es una referencia para mostrar la problemática que generó la apertura de casas de moneda en las entidades federativas. El 31 de mayo de 1825 la Compañía Anglo Mexicana tomó el control administrativo de la ceca guanajuatense (Parra, 1998, pp. 159-163). Se trataba de una empresa representada desde febrero de ese año por la casa comercial Manning y Marshall, firma británica cónsul de uno de los acree- 
dores importantes del gobierno mexicano: Barclay, Herring, Richardson y Compañía (Martínez, 2015, p. 25). El arrendamiento en Guanajuato debía durar diez años, los cuales iniciaban cuando la Anglo Mexicana concluyera con las adecuaciones al edificio y la instalación de la maquinaria, otorgándole un plazo de un año para ello 3

Los británicos tuvieron dificultades para cumplir con los ajustes en el establecimiento. Dos años después de la firma del contrato, la comisión de Hacienda del congreso local informó que la compañía instalaría un apartado y finalizaría las obras de rehabilitación en seis meses. Aunque se acordó que el arrendamiento daría inicio el 24 de abril de 1828, los problemas para poner en funcionamiento el apartado persistieron durante los siguientes meses (Sanabria, 1830, p. 12), tal como puso de manifiesto la nueva prórroga por cuatro años adicionales a los primeros diez aprobada el 18 de mayo de 1830. A cambio de esta, los empresarios se comprometieron a terminar la instalación en un tiempo máximo de un año. Con estas modificaciones, el arrendamiento debía terminar el 24 de abril de 1842,4

Las complicaciones para poner en marcha la ceca de Guanajuato eran muestra de que en los estados no siempre fue sencillo impulsar la apertura de casas de moneda con capital privado ${ }^{5}$ Existieron casos como en Chihuahua donde el Congreso estatal decretó en 1825 la necesidad de poner en funcionamiento una ceca, para lo cual se invitó a todos los inversionistas interesados a que hicieran llegar sus propuestas al Congreso local ${ }^{6}$ Sin embargo, el decreto no tuvo repercusión pues dos meses y medio más tarde, el 23 de septiembre, se ordenó publicarlo en la prensa explicando el principal motivo para promover la apertura de la casa de moneda: se trataba de un ramo que beneficiaría al erario del Estado $7^{7} \mathrm{El} 22$ de diciembre de ese mismo año el Congreso chihuahuense autorizó que la apertura y gestión de la casa de moneda se diera por medio de un contrato de arrendamiento y especificó que se tomaría como modelo para tal fin el contrato firmado entre Ricardo Exter y las autoridades del Estado de Occidente en septiembre de 1825.8 No obstante, la ceca de Chihuahua tardaría algunos años en ponerse en funcionamiento, pues fue hasta 1832 cuando inició operaciones financiada por el gobierno estatal y a partir del 7 de marzo de 1839 fue arrendada al empresario extranjero Juan Kelly bajo condiciones muy similares a las que se habían dado en Guanajuato (Gutiérrez, 1849, pp. 20-21).

\footnotetext{
${ }^{3}$ Contrata de Casa de moneda celebrada entre el supremo gobierno del estado de Guanajuato y don Juan Guillermo Williamson, 31 de mayo de 1825, carpeta 626, f. 8, caja 77, Fondo Hacienda Pública-Archivo Central (en adelante FHPAc), Archivo General de la Nación (en adelante AGN), México.

${ }^{4}$ Contrata de Casa de moneda celebrada entre el supremo gobierno del estado de Guanajuato y don Juan Guillermo Williamson, 31 de mayo de 1825, carpeta 626, f. 12, caja 77, FHPAC, AGN.

${ }^{5}$ Conviene señalar que no era la primera vez que el capital británico se había topado con dificultades para echar a andar empresas ligadas al ramo minero. Desde 1824 existió el interés por invertir en la minería mexicana, sobre todo mediante la introducción de tecnología como la máquina de vapor para desaguar minas y de innovaciones en el beneficio de metales. De hecho, la compañía Anglo Mexicana llegó al país a invertir en minas guanajuatenses. Sin embargo, como muestra Alma Parra (2014, pp. 149-155), el legado de la tecnología británica en la minería mexicana fue limitado. Tuvo que enfrentar la ausencia de infraestructura en caminos, así como las inclemencias derivadas de las burbujas financieras en Londres. En ese sentido, es sintomático lo dicho en una memoria del gobierno de Guanajuato respecto al atraso en el funcionamiento de la ceca local: "el empresario estaba cansado de esperarse y de hacer gastos inútiles, especialmente del ingeniero que vino de Londres solo a dirigir el taller”. Memoria del estado de Guanajuato, 1826, VIII-4, 13.695.1, 2 fs, Colección Román Beltrán (en adelante CRB), Centro de Estudios de Historia de México Carso (en adelante СЕHм).

${ }^{6}$ Decreto 53, 4 de junio de 1825, vIII-4, 12.613.1.0001, f. 1, CRB, CEHM, Chihuahua.

${ }^{7}$ Orden 70, 23 de septiembre de 1825, vIII-4, 12.638.1.0001, f. 1, CRB, CEHM, Chihuahua.

${ }^{8}$ Decreto 105, 22 de diciembre de 1825, vIII-4, 12.649.1, f. 1, CRB, CEHM,.Chihuahua.
} 
Del caso anterior destacan la imposibilidad de abrir la ceca por la vía del arrendamiento, lo que denota las complicaciones vistas por los inversionistas para una empresa compleja como esta, así como la mención que se hace de Ricardo Exter y la Casa de Moneda del Estado de Occidente. Exter fue un comerciante británico que llegó a territorio mexicano tras la consumación de la independencia y fungió como socio de la Exter, Graves and Company, empresa que tenía vínculos con la General Pearl and Coral Association de Londres ${ }^{9}$ Exter destacó por su actividad como aviador de minas en el occidente de México y estableció varios contratos para la explotación de pequeños reales mineros de plata que en 1825 le reportaron ingresos por 153000 pesos (Mayo, 2006, pp. 92-93). Al igual que sus colegas y compatriotas de la Compañía Anglo Mexicana, Exter buscó integrar el negocio de la minería con el de la acuñación. Su nombre apareció en dos contratos cuyo fin era el arrendamiento de casas de moneda dentro de la geografía occidental del país.

El 2 de marzo de 1825 el congreso de Jalisco autorizó la celebración de un contrato para arrendar la Casa de Moneda de Guadalajara, un establecimiento de acuñación que, según Bonifacio Gutiérrez (1849, p. 28), había sido abierto en 1812 bajo la coyuntura de la guerra, mismo que fue clausurado en 1815 y oficialmente reconocido el 21 de agosto de 1821 . Dicho contrato fue otorgado a Ricardo Exter quien debía hacerse cargo de la administración de la ceca durante un plazo de diez años, asumir los gastos de rehabilitación y proveerla de maquinaria. Dentro de sus responsabilidades estaba cubrir los salarios del ensayador y del interventor, el primero nombrado por el gobierno federal y el segundo por el estatal. Además, se le obligó al pago de una renta cuyo monto sería acordado con el gobierno del estado; aunque se estipuló que adelantaría 10000 pesos al erario estatal para amortizar la renta. Este fue un elemento característico de los contratos de arrendamiento: el adelanto de liquidez amortizable con el flujo de ingresos futuros 10

El segundo contrato se dio seis meses después, el 29 de septiembre de 1825, cuando el gobierno del Estado de Occidente publicó un documento que contenía la contrata para abrir una casa de moneda en su territorio mediante el arrendamiento a Ricardo Exter. Dentro del convenio se estipuló que el arrendatario debía acondicionar un edificio para la ceca y comprar e instalar la maquinaria necesaria; al término de este, el gobierno estatal cubriría el costo del edificio, pero no el de la maquinaria. El plazo del arrendamiento era de doce años tras los cuales la casa de moneda debía ser operada por el gobierno del estado. El contrato serviría como un mecanismo de financiamiento para la apertura de la ceca. 11

En la contrata del Estado de Occidente aparece como apoderado de Ricardo Exter un personaje de nombre José Antonio Herrera, comerciante chileno que se desempeñó como cónsul general en México y que estableció su residencia en Tepic, ciudad que había empezado a emerger como centro de operaciones comerciales a la par del puerto de San Blas.12 Miembro de la Herrera, Ritchie y Compañía, Herrera también fue socio de Archibald Ritchie, mercader británico que tenía su

\footnotetext{
${ }^{9}$ Ricardo Exter se casó en la Ciudad de México con María Dolores Soto y Saldaña en agosto de 1825. En noviembre de 1826 compró la mitad de una concesión para la colonización de un extenso territorio al este de lo que hoy día es Nuevo México, el suroeste de Kansas, el sureste de Colorado, y los salientes de Texas y Oklahoma. Falleció en junio de 1829 (Estep, 2010).

${ }^{10}$ Orden del mismo día, 2 de marzo de 1825, viII-4, 13.680-1, pp. 1-5, Colección de los decretos y órdenes del honorable Congreso constitucional del estado libre de Jalisco, 1826, CRB, CEHM.

${ }^{11}$ Véase Artículos (1825, pp. 2-3).

${ }^{12}$ Respecto a la conformación de una economía regional en torno a la ciudad de Tepic y el papel que desempeñó en ello el engranaje comercial, marítimo y minero con San Blas, Mazatlán, Guadalajara y El Rosario, véase Contreras (2017, pp. 40-65).
} 
centro de operaciones en Guadalajara, donde también hacía negocios a nombre de Exter. Ritchie se convirtió en un contacto obligado para cualquier británico que llegaba a Guadalajara en busca de negocios (Contreras, 2017, pp. 79-80; Mayo, 2006, pp. 79-80).

Todo lo anterior permite destacar los intereses británicos en el control del circuito de producción, extracción, acuñación y exportación de metales en el occidente mexicano ${ }^{13}$ Los arrendamientos de las casas de moneda de Guadalajara y del Estado de Occidente representaban el control por parte de Exter de la amonedación de los metales extraídos de un conjunto de realillos mineros esparcidos en una amplia zona del noroeste de Jalisco, el sur de Sinaloa y las partes serranas del sur de Durango y Chihuahua. Esta región se caracterizó por la ausencia de grandes vetas, pero contaba con una gran cantidad de medianas y pequeñas minas, situación que había colocado a los aviadores británicos en una posición estratégica dentro del espacio minero del occidente del país (Contreras, 2017, pp. 42-48).

Sin embargo, ninguno de los dos contratos de arrendamiento entró en vigor, de modo que Ricardo Exter nunca ejerció como arrendatario de la ceca de Guadalajara. Un observador de la época, Juan Nepomuceno Sanabria, al referirse a este evento, sostiene que "el gobierno de aquel estado en todo tiempo lo ha procurado perfeccionar [el establecimiento] y los tiene en corriente [sus gastos] hasta el día” (Sanabria,1830, p. 16). Bonifacio Gutiérrez (1849, pp. 28-29) menciona que la ceca tapatía se encontraba bajo la administración del gobierno durante su gestión como ministro de Hacienda, es decir, entre julio y octubre de 1849 y así debió de permanecer hasta 1857 cuando, según Martha G. Sánchez (2003, p. 81), fue arrendada por primera vez. Por su parte, la Casa de Moneda del Estado de Occidente nunca fue abierta, pues, debido a las vicisitudes políticas, esta entidad federativa quedó dividida a finales de 1830 en los estados de Sonora y Sinaloa. Fue hasta 1861 cuando se abrió la primera casa de moneda en Sonora -Hermosillo y Álamos-, mientras que en Sinaloa se empezó a acuñar moneda en 1846 en la ceca de Culiacán (Matamala, 2008, p. 71; Romero, 2001, pp. 58).

Los contratos mencionados ponen en evidencia el interés británico por tener posiciones estratégicas en la acuñación de plata producida en el occidente del país, así como por abrir y habilitar casas de moneda estatales. Esto permite sostener que el primer federalismo motivó la apertura de cecas en los estados y que los gobiernos locales vieron una alternativa en el arrendamiento para su puesta en marcha, pero tal y como revelan los casos de Guadalajara y el Estado de Occidente, estos no siempre se concretaron y aún en aquellos lugares en donde sí fueron posibles, como en Guanajuato, hubo dificultades. Las expectativas de ganancias al arrendar una casa de moneda eran altas, pero la rentabilidad dependía de factores como los intereses regionales, las complicaciones materiales, la ubicación, la cercanía de las minas y la presencia de otras cecas.

La apertura de casas de moneda regionales no había sido bien vista por las autoridades del centro del país desde la época de la acuñación provisional. Dentro del orden de la Primera República Federal fueron reconocidas como parte de las potestades de los estados, no obstante, el proceso de redefinición de estas a lo largo del siglo XIx buscó su traslado al ámbito del poder nacional. Si bien es cierto que el viraje al centralismo en 1836 fue el primer paso para que el gobierno nacional tuviera injerencia sobre los ingresos de las cecas, también dependió de los márgenes que otorgaron los poderes locales. El control de los ingresos de las cecas por parte del erario nacional implicó un proceso de negociación que se vio reflejado en las reparticiones de rentas de 1846 y 1857, pues en ellas se reveló que los ingresos generados por las cecas formaban parte de las rentas de la fe-

${ }^{13}$ Sobre el capital de origen británico en la minería mexicana, véase Parra (2014, pp. 141-163). 
deración (Velasco, 2016, pp. 110-113, 151) 14 Otra dificultad ligada a la apertura de las casas de moneda regionales fue la ocasionada por la exportación de plata en pasta, que para el caso de la ceca de Culiacán, estuvo relacionado con el espacio mercantil de la costa occidental del país.

El 9 de mayo de 1830 apareció una editorial en el Correo de la Federación Mexicana que calificaba de asunto inútil y perjudicial la apertura de casas de moneda $\sqrt{15}$ Esta valoración, procedente de un medio oficial, debe leerse como el colofón argumentativo de la ley del 19 de julio de 1828 que autorizó la extracción de metales en pasta $\sqrt{16}$ Desde la perspectiva del editorialista, la amonedación debía estar limitada a cubrir las necesidades relacionadas con los intercambios, mientras que aquellos metales cuya acuñación era innecesaria debían salir del país sin restricciones para beneficio de los mineros. Para el autor era claro que "bastarían dos o lo más tres casas convenientemente situadas, es decir en puntos medios de los minerales de la República, y a bastante distancia la una de la otra a fin de que no se perjudicasen mutuamente" (Sanabria, 1830, p. 5).

El 1 de junio de 1830 Juan Nepomuceno Sanabria, ensayador y juez de balanza en la Casa de Moneda de San Luis Potosí, redactó un folleto en donde daba respuesta a la editorial del Correo de la Federación. Para el funcionario potosino, la libre exportación de oro y plata en pasta era una medida que tenía efectos nocivos para los sectores encadenados con el funcionamiento de las casas de moneda estatales. Su planteamiento apeló a los efectos multiplicadores que la acuñación había generado en las economías regionales pues la amonedación requería maquinaria, brazos y una cantidad importante de insumos como cobre, plomo, carbón y leña. La consecución de estos materiales beneficiaba a los sectores de la población más necesitados, quienes, en conjunto con los operarios, eran las clases más perjudicadas de una política que limitaba la producción de las casas de moneda en los estados (Sanabria, 1830, p. 5).

El análisis de Sanabria plantea dos discusiones. Primero, el de la conveniencia de continuar o no con la apertura de las casas de moneda, que databa de 1815, cuando se buscó la clausura de las cecas provisionales -la propuesta del editorialista de mantener abiertas sólo tres casas de moneda, manifiesta la continuidad de este debate-, y de acuerdo con el Correo de la Federación, la existencia de muchas cecas favorecía la falsificación y le restaba calidad al cuño nacional (Sanabria, 1830, pp. 21, 25). Esto expresaba el interés del gobierno mexicano por monitorear las casas de moneda estatales en un aspecto en el que sí tenía injerencia, es decir, en la regulación de la calidad de la moneda ${ }^{17}$ Estamos ante dos críticas por parte del gobierno nacional, una referente a la cantidad de cecas y otra respecto a la baja calidad de los cuños. Esta observación daba muestra del interés del gobierno por aumentar su capacidad de monitoreo a la acuñación reduciendo los puntos de vigilancia.

\footnotetext{
${ }^{14}$ Véase la clasificación de rentas del 17 de septiembre de 1846 en Dublán y Lozano (1876, t. v, p. 170) y la del 12 de septiembre de 1857 (Dublán y Lozano, 1876, t. viII, p. 622).

${ }^{15}$ Es necesario acotar que lo que referimos sobre la editorial se desprende de lo que Juan Nepomuceno Sanabria (1830) describe de ella. El trabajo de Sanabria es una respuesta a la editorial del 9 de mayo del Correo de la Federación Mexicana y cita partes textuales de la misma. No ha sido posible revisar dicha editorial pues no se localiza el número al que se hace referencia.

${ }^{16}$ Ley que permite la extracción de oro y plata en pasta, 19 de julio de 1828 en Dublán y Lozano (1876, t. II, p. 75).

${ }^{17} \mathrm{El}$ artículo 50 fracción xv de la Constitución de 1824 estableció que el congreso debía "Determinar y uniformar el peso, ley, valor, tipo y denominación de las monedas en todos los estados de la federación”. Un decreto del 16 de noviembre instruyó que le correspondía al ministerio de Hacienda inspeccionar las casas de moneda. Su trabajo debía ser monitorear el peso, ley, tipo, valor y denominación de las monedas (Dublán y Lozano, 1876, t. I, pp. 724, 740).
} 
La segunda discusión está vinculada con la posibilidad de exportar plata y oro en pasta, una política que afectaba a quienes tenían intereses en las casas de moneda. Los argumentos que defendían la exportación de metales sin acuñar eran los mismos que Sanabria había esbozado en su análisis a favor de las cecas estatales: la minería se beneficiaba y la población vinculada a ella también. Si ambas posturas apelaban al mismo argumento es necesario preguntar en dónde radicaba la diferencia. Desde nuestra perspectiva, la respuesta está en la incidencia fiscal definida por la repartición de rentas de agosto de 1824 que dejó en manos del erario federal todos los ingresos derivados del comercio exterior, mientras que los generados por las cecas quedaron bajo control de los estados.

Además de la retórica detrás de la búsqueda de beneficios para la minería, la posibilidad de exportar plata en pasta tenía como objetivo incrementar los ingresos del erario nacional. La demanda de plata en el extranjero, sobre todo por parte de los comerciantes británicos, había sido una constante desde principios del siglo xix. La posibilidad de sacarla del país en pasta significaba conectar la dinámica exportadora del metal con las necesidades del erario nacional. Las casas de moneda estatales y los intereses generados por ellas entraron en contradicción con esta medida, pues la perspectiva lucrativa de arrendarlas disminuía en un contexto en el que era posible extraer el metal del país sin necesidad de involucrarse en el proceso de acuñación. Es probable que tal circunstancia haya sido una de las razones por las cuales algunos de los proyectos de arrendamiento en el occidente del país no lograron concretarse pues la salida de plata sin acuñar por las costas de esa zona del país fue relevante y tolerada.

La ley del 19 de julio de 1828, que autorizó la exportación de plata y oro en pasta, estableció 7 \% de impuesto sobre el valor de los metales, el cual debía ser cobrado en la aduana en el momento de su extracción. Si bien esta flexibilización en el comercio de metales sin acuñar tuvo vaivenes a nivel nacional, fue una política más duradera para los metales extraídos por puertos del occidente como San Blas, Mazatlán y Guaymas, lo que colocó a la ceca de Culiacán en el complejo entramado de intereses por la exportación de plata en pasta y la presencia de los arrendamientos. A continuación, un recorrido por las condiciones comerciales de esta zona del país permite explicar el porqué de esta continuidad.

\section{CONDICIONES DEL COMERGiO EN LA COSTA OCGIDENTAL MEXICANA Y REGULACiÓN DE LA EXPORTACiÓN DE} PLATA EN PASTA DURANTE LA PRIMERA MITAD DEL SIGLO XIX

\section{Condiciones del comercio}

$\mathrm{Al}$ consumarse la independencia de México, San Blas era el principal nodo de comercio de la costa occidental del país. La presencia de los intereses británicos en este puerto hizo posible mantener su preeminencia hasta la década de 1830. A pesar de que las condiciones naturales de San Blas nunca fueron las mejores, su dinámica estuvo ligada a Tepic, un poblado con un clima menos hostil que sirvió como bisagra de comercio entre la costa y Guadalajara (Contreras, 2017, p. 18). Debido a estas condiciones, Tepic se convirtió en un centro político y económico de relevancia, prueba de ello fue que en 1824 se estableció ahí el consulado británico y la aduana del puerto, a pesar de las 18 leguas de distancia entre los dos puntos (Mayo, 2006, p. 33). La órbita de influencia británica en el eje San Blas-Tepic-Guadalajara se consolidó con la presencia del cónsul Eustaquio 
Barrón, socio de la firma Barron y Forbes establecida en Tepic desde 1823 18 Con jurisdicción consular en Mazatlán y Guaymas, la influencia británica en la zona se mantuvo a la par que San Blas fue cediendo terreno frente a Mazatlán en importancia como puerto de altura en el Pacífico, un proceso que empezó a darse a partir de la década de 1830 (Herrera, 1988a, pp. 131-132; Ibarra, 1998, p. 423).

Desde 1820 las cortes españolas habían permitido el comercio exterior a través de Mazatlán, pero fue hasta 1822 cuando entró en operaciones. Araceli Ibarra (1998, p. 387) sostiene que el crecimiento del puerto fue veloz, a tal grado que en 1828 fue necesario colocar una aduana federal que ya existía en El Rosario, importante poblado minero. Las condiciones de Mazatlán, tanto climáticas como geográficas, eran mejores que las de San Blas, además de que su posición en la entrada del Golfo de California y en el centro del litoral del Pacífico mexicano resultaba estratégica para el comercio marítimo. Contaba con un hinterland que le dio ventajas como centro de abastecimiento de los navíos que hacían recorridos desde Guayaquil y hasta San Francisco, situación que fue determinante tras el auge aurífero del norte de California en 1849. La zona de influencia del puerto sinaloense articuló la producción minera y agrícola. Desde Mazatlán era posible acceder a los minerales de El Rosario, Copala, Pánuco, Guadalupe de los Reyes y San Vicente (véase mapa 1). En materia agrícola, poblados como Cosalá, San Sebastián y Rosario suministraron maíz, frijol, café, arroz, frutos y palo de Brasil, este último como mercancía de exportación. Se conectó vía terrestre con el sur de Durango y de Chihuahua, así como con el eje Tepic-Guadalajara. El cabotaje permitió el comercio a lo largo de la costa hacia otros puntos de Sinaloa, Sonora y las costas de la Alta California (Busto, 2008, pp. 234-236; Mayo, 2006, p. 55).

Estas condiciones favorecieron la llegada de casas comerciales extranjeras al puerto de Mazatlán que comenzaron a destacar en la vida económica y política del estado, lo que consolidó este puerto como el de mayor movimiento marítimo del oeste mexicano (Herrera, 1988a, p. 132). Arturo Román (1998, p. 19) indica que en 1845 había trece casas comerciales extranjeras, entre ellas seis de origen alemán. Aunque el peso y presencia de los comerciantes alemanes en Mazatlán era destacado (Mentz, 1982, p. 131), la empresa más importante fue la Jecker-Torre y Compañía, encabezada por Isidoro de la Torre, comerciante de origen español, y Juan Bautista Jecker, inmigrante suizo con residencia en la capital del país.19 La compañía se dedicó al comercio por comisión, la exportación e importación de mercancías, el otorgamiento de préstamos, así como a la emisión y el descuento de letras de cambio. Además, estuvo relacionada con el financiamiento

\footnotetext{
${ }^{18}$ La firma Barron y Forbes fue relevante en el comercio por la Costa Occidental mexicana. Se trató de una compañía impulsada por el peso diplomático británico y el interés por los recursos de la Alta California. En este sentido, uno de los hechos relevantes de la firma fue el control que tuvo de la mina de mercurio de Nuevo Almadén, en Santa Clara, California, desde 1847 y hasta 1863 cuando la Suprema Corte de Justicia estadunidense confiscó la mina a la New Almaden Company, bajo control de la Barron y Forbes (Herrera, 1988b, pp. 160-163).

${ }^{19}$ Isidoro de la Torre y Carsi comenzó su carrera empresarial dentro de la compañía Tomás de la Torre, Jecker y Cía. fundada en 1844. A principios de 1847 cambió de nombre a Jecker-Torre y Cía., dentro de la cual había tres socios: Juan Bautista Jecker, Isidoro de la Torre y Felipe Alonso Terán. Desde la época de Tomás de la Torre, posible tío de Isidoro, la empresa se vinculó al comercio en Veracruz, Tampico y Mazatlán. En 1846 logró un contrato para abastecer a las Californias con víveres, vestuario y armamento en pleno conflicto armado con Estados Unidos. Esto afianzó la presencia de la compañía en el occidente del país, en especial en Mazatlán, hacia la década de 1850. Del mismo modo hizo posible la expansión comercial de la firma hacia el noroeste mexicano y San Francisco, epicentro del auge aurífero californiano. En 1855 se disolvió la Jecker-Torre y Cía., no obstante, la sociedad continuó operando en la capital y en el puerto de Mazatlán bajo la razón social de Juan B. Jecker y Cía. A partir de ese momento Isidoro de la Torre comenzó a incrementar su actividad como hacendado, situación que lo colocó como un importante productor azucarero hacia la segunda mitad del siglo XIX (Bernecker, 1992, pp.177-179; Huerta, 1981, pp. 167-170; 1993, pp. 58-61).
} 


\section{MAPA 1. PUERTOS, CASAS DE MONEDA, CIUDADES Y MINERALES DE LA COSTA OCGIDENTAL MEXICANA}

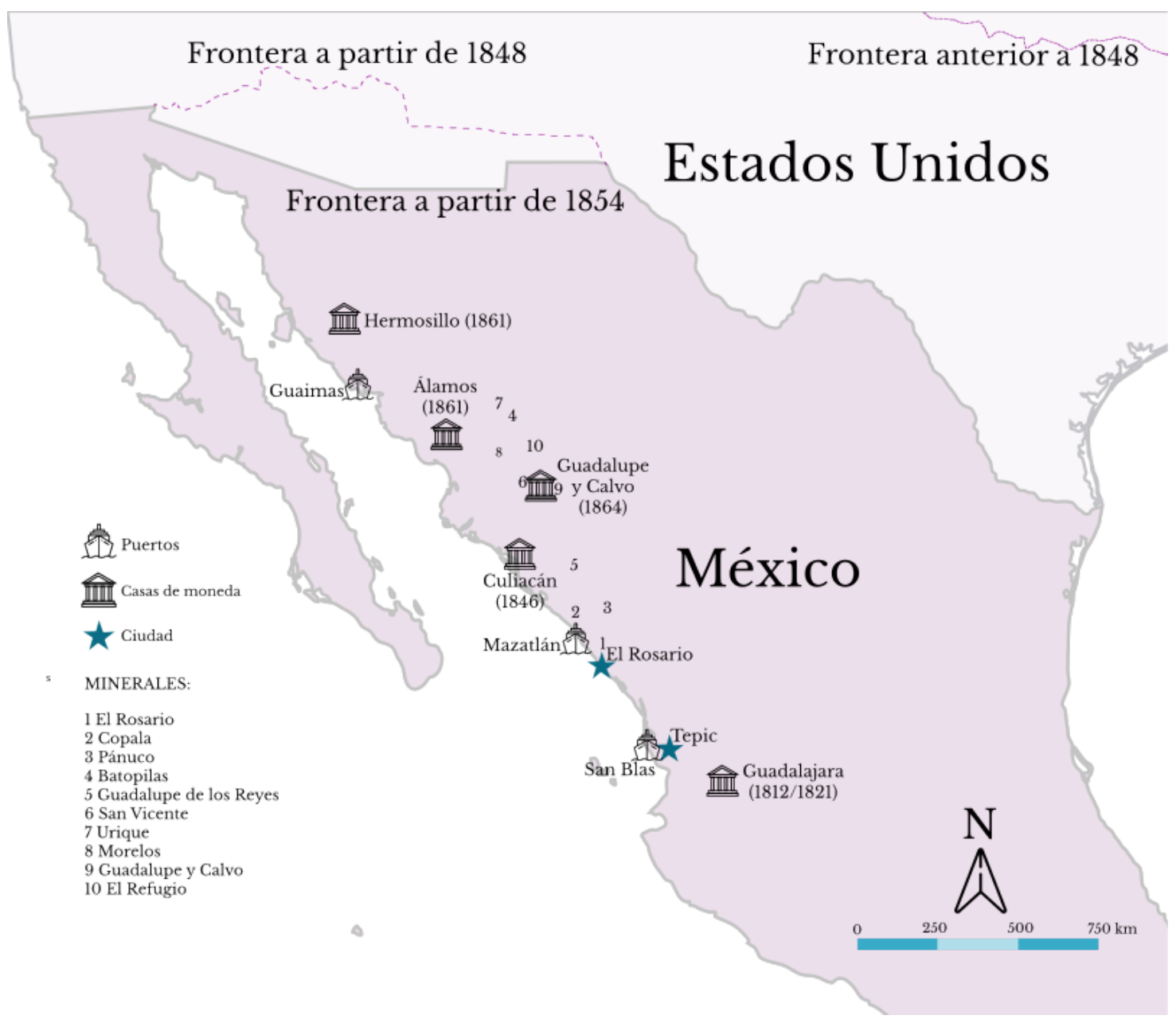

Fuente: elaboración propia con base en Beltrán (2003, p. 4).

del sector minero -en especial a Veta Grande en Zacatecas- y firmó convenios con la Junta de Fomento y Administrativa de Minería para hacerse cargo de la recaudación del real por marco cobrado a la plata. Su papel como prestamista del gobierno le llevó a inmiscuirse en las llamadas convenciones inglesa, francesa y española, y arrendó la Casa de Moneda de Culiacán, aunque su paso como contratista en este rubro fue efímero (Huerta, 1981, pp. 173; Huerta, 1993, pp. 54-55; Mayo, 2006, p. 55).

De acuerdo con Ibarra (1998), Mayo (2006) y Mentz (1982), no es fácil la construcción de series que permitan una perspectiva amplia del comercio por las costas del occidente mexicano durante la primera mitad del siglo xix. Por una parte, debe notarse la relevancia que tuvieron las entradas derivadas de las importaciones -tomadas como indicador comercial (véanse cua- 


\section{GUADRO 1. INGRESOS ADUANALES POR IMPORTACIONES (M) Y EXPORTACIONES (X), 1825-1856 (PESOS DE LA ÉPOCA).}

\begin{tabular}{|c|c|c|c|c|c|c|}
\hline \multirow[b]{2}{*}{ Año } & \multicolumn{2}{|c|}{ Mazatlán } & \multicolumn{2}{|c|}{$\begin{array}{c}\text { San Blas, Guaymas } \\
\text { y Mazatlán(total) }\end{array}$} & \multicolumn{2}{|c|}{$\begin{array}{l}\text { Proporción de Mazatlán } \\
\text { en el total (porcentaje) }\end{array}$} \\
\hline & Importaciones & Exportaciones & Importaciones & Exportaciones & Importaciones & Exportaciones \\
\hline 1825 & 15665 & 14490 & 158265 & 17892 & 9.9 & 81 \\
\hline $1826-1827$ & 164268 & 2800 & 282406 & 12036 & 58.2 & 23.3 \\
\hline $1827-1828$ & 66168 & 8361 & 162283 & 17234 & 40.8 & 48.5 \\
\hline $1830-1831$ & 96557 & 13527 & 625108 & 26242 & 15.4 & 51.5 \\
\hline $1833-1834$ & 157215 & 10735 & 304148 & 12265 & 51.7 & 87.5 \\
\hline
\end{tabular}

Fuente: elaboración propia con base en Mayo (2006, p. 189).

dro 1 y gráfica 1) - respecto a las que generaron las exportaciones; esto habla del nivel de consumo del mercado interno que demandó textiles de algodón, hilos, sedas, vinos, ferretería y azogue, este último vinculado a la minería (Ibarra, 1998, pp. 383, 390; Mentz, 1982, p. 129).

Por otro lado, resalta el peso específico del puerto de Mazatlán respecto a San Blas y Guaymas. A partir del año fiscal 1833-1834, el puerto sinaloense comenzó a ganar relevancia, sobre todo si consideramos el rubro de los ingresos generados a través de las exportaciones. El nivel de ingresos generados por las exportaciones en Mazatlán se corresponde casi con el total de los tres puertos (véase gráfica 1). A nivel nacional, el principal producto de exportación fue la plata, patrón que se replicó en el puerto más importante del occidente mexicano. Los datos muestran que, entre 1824 y $1828,75 \%$ de las exportaciones nacionales fueron metales, sobre todo plata amonedada (Herrera, 1977, pp. 60-61). Esto significó un promedio anual de 6891308 pesos durante dicho periodo. Aunque no contamos con datos tan tempranos para el caso de Mazatlán, para fines referenciales, tomemos el que ofrece Arturo Román (1998, p. 51), quien muestra que 72 \% de las exportaciones hechas por Mazatlán en 1854 eran metales preciosos.

Sin duda, la plata como producto de exportación fue predominante durante el siglo xIx, pero calcular el monto exacto de la salida de este metal, sobre todo durante la primera mitad del siglo, se ha topado con complicaciones derivadas de la presencia del contrabando. Miguel Lerdo de Tejada (1853, pp. 58-60) recalcó en su momento que una parte importante de la extracción de metales se hacía ilícitamente, aunque según sus cálculos, entre 1825 y 1851 había salido del país un promedio anual de 9120233 pesos por la vía legal; el monto de la salida de metales por el camino del contrabando era de una magnitud similar. Basado en los datos disponibles sobre derechos pagados por la exportación, el nivel de las importaciones y el estado de la minería, el político veracruzano llegó a la conclusión de que salían del país entre 23000000 y 24000000 de pesos en oro y plata al año. 


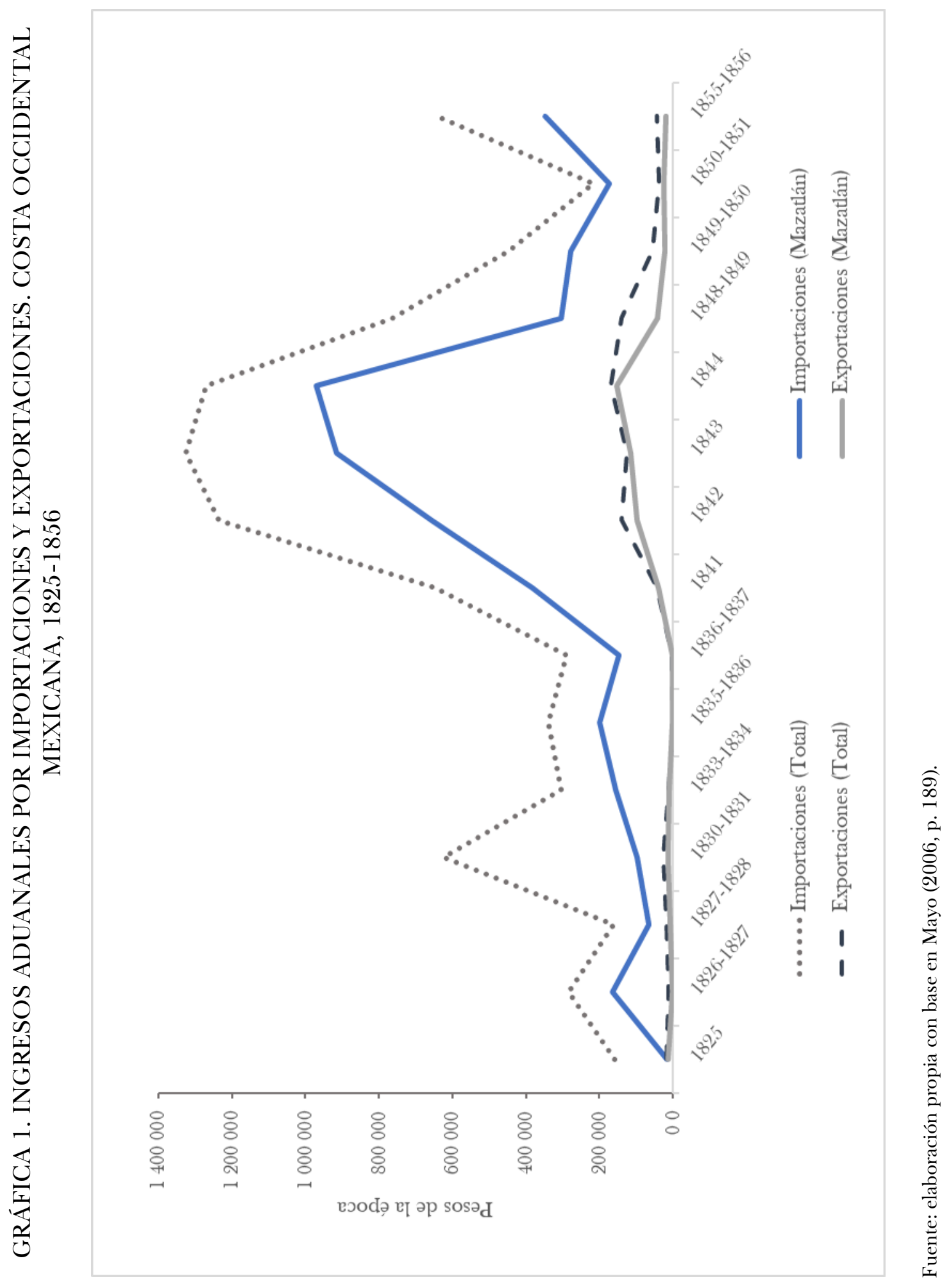




\section{GUADRO 2. EXPORTACIÓN DE METALES POR LOS PUERTOS DEL PACÍFICO MEXICANO 1834-1842 (PESOS DE LA ÉPOCA).}

\begin{tabular}{|c|c|c|c|c|}
\hline Año & $\begin{array}{c}\text { Total, por los } \\
\text { tres puertos }\end{array}$ & San Blas & Mazatlán & Guaymas \\
\hline 1834 & 1436000 & 25000 & 151000 & 10000 \\
\hline 1835 & 1557140 & 78000 & 113140 & 66000 \\
\hline 1836 & 2321617 & 440000 & 1518570 & 363047 \\
\hline 1837 & 2270488 & 0 & 2270488 & 0 \\
\hline 1838 & 3150425 & 675000 & 542000 & 0 \\
\hline 1839 & 2373568 & 26500 & 17850 & 1641608 \\
\hline 1840 & 4737625 & 336000 & 1442000 & 0 \\
\hline 1841 & 2969135 & 557981 & 1254640 & 432885 \\
\hline 1842 & 3224965 & 214981 & 1311779 & 321569 \\
\hline Promedio anual & 2671218 & 261496 & 957941 & 315012 \\
\hline
\end{tabular}

Nota: el total no es la suma de los tres puertos. Araceli Ibarra (1998) registró allí datos de la exportación de metales en los que no se especificaba su punto de salida, pero que habían sido extraídos por alguno de estos tres puertos.

Fuente: elaboración propia con base en Ibarra (1998, pp. 547-550).

Por su parte, Ibarra (1998, pp. 190-200) construyó una serie de la exportación de plata a partir de fuentes consulares y la compara con las cifras oficiales de acuñación. Este ejercicio revela que el agregado de la plata registrada por los consulados británico, estadunidense y francés supera lo que fue acuñado a través de las casas de moneda. De este modo, entre 1826 y 1841 salieron del país 80335797 pesos más de los que se acuñaron, esto significa un promedio anual de 5355719 pesos durante el periodo. El resultado brinda una magnitud más clara de lo que pudo haber sido extraído como contrabando en forma de plata pasta y a través de embarcaciones británicas, pues los montos más grandes fueron registrados por ellas. Este asunto a nivel de las costas del occidente mexicano fue de gran relevancia, ya que la extracción de plata pasta y el contrabando contaron para su ejecución con la participación de las casas comerciales 20 El cuadro 2 muestra algunos de los registros de los metales extraídos de manera legal por los puertos del occidente mexicano entre 1834 y 1842 , periodo para el que existe información completa.

Durante el periodo contemplado, en promedio salieron anualmente por la vía legal poco más de 2500000 pesos por los tres puertos del Pacífico. Una cantidad importante si consideramos que ilícitamente pudieron haber salido a nivel nacional un estimado de 5500000 pesos. De Mazatlán salió una media anual de 957941 pesos, cifra con certeza subvalorada pues en el registro total aparecen metales de los que no especifica su punto de salida y que pudieron haber sido extraídos por allí. Aun así, del puerto sinaloense salió más metálico durante el periodo considerado. La estimación del contrabando por estos nodos del Pacífico excede los objetivos de este trabajo,

${ }^{20}$ La casa comercial Melchers, de origen alemán y fundada en Mazatlán en 1846 (Mentz, 1982, p. 132), se vio involucrada en un episodio de contrabando de plata a través del barco India. Para Ibarra (1998, p. 392), la Melchers y Compañía fue la firma contrabandista por excelencia en el puerto. Por su parte, Mayo (2006) muestra los informes del capitán Henry Byam Martin, a cargo del barco Grampus y encomendado para recolectar plata en la costa del Pacífico mexicano. Al referirse a Isidoro Torre, socio de la Jecker-Torre y Compañía, Byam dice: "sin duda es el más importante contrabandista de Mazatlán, así como Forbes lo es en San Blas” (Mayo, 2006, p. 55). 
sin embargo, existe evidencia cualitativa que da cuenta de cómo la situación del tráfico ilegal de plata por esta zona del país fue una preocupación para los distintos gobiernos mexicanos. Esta evidencia la abordamos a continuación al hacer un recorrido por los cambios en la regulación de la exportación de plata en pasta durante la primera mitad del siglo xix.

\section{La regulación de la exportación de la plata en pasta}

El 15 de diciembre de 1821 se estableció la primera estructura arancelaria del México independiente. La Soberana Junta Provisional Gubernativa suscribió ese día un documento en donde daba las directrices de la política comercial del imperio mexicano (Dublán y Lozano, 1876, t. I, p. 567). Nada se dice sobre prohibir la extracción de plata y oro en pasta, pero se entiende que estaba permitida en la medida en la que quedó definido el pago de derecho por su exportación. De este modo, la salida de plata acuñada pagaría $3.5 \%$, la plata labrada $3 \%$ y la plata en pasta $5.5 \%$. Sin embargo, un mes después, el 14 de enero de 1822, fue emitido un decreto en el que quedaba prohibida. La medida era la respuesta a una representación que la regencia había hecho a la Junta el 4 de enero de 1822 (Dublán y Lozano, 1876, t. I, pp. 586, 588).

Durante el proceso de transición al orden federal, el ministro de Hacienda, Francisco de Arrillaga, presentó el 13 de enero de 1824 una memoria en donde proponía al Congreso Constituyente una serie de reformas al arancel mercantil de diciembre de 1821. Dentro de sus propuestas destaca una relacionada con los metales en pasta. $\mathrm{Al}$ respecto, sostuvo que en las provincias de occidente, Sonora y Sinaloa, había una constante carencia de numerario para el comercio interno y externo. Esta situación empeoraba ante la lejanía de los centros de acuñación, por lo que en aquella zona del país los intercambios con metales en pasta eran comunes. Ante esto, Arrillaga propuso una excepción a la ley que permitiría la extracción de plata y oro sin acuñar en esa región "para que el erario no pierda los derechos que percibiría en tal caso, a lo menos por ahora, y hasta que pueda situarse más cerca alguna casa de moneda" (Tardiff, 1968, pp. 217, 225). Esta particular dinámica obligaba a segmentar la política comercial en relación con la plata en pasta.

Sin embargo, la prohibición se mantuvo en el arancel general del 16 de noviembre de 1827. Dentro del capítulo 4, el artículo 41 dice que se prohibía, bajo pena de comiso, la exportación de oro y plata en pasta. La plata acuñada y labrada podía salir del país tras el pago de una tasa de $3.5 \%$. Como ya hemos dicho, el 19 de julio de 1828 se expidió una ley que derogó el artículo 41 del arancel de noviembre de 1827 por lo que la plata en pasta podía salir del país pagando una tasa de siete por ciento. (Dublán y Lozano, 1876, t. II, pp. 30, 75).

$\mathrm{Si}$ atendemos a lo que sostiene Lerdo (1853), los vaivenes en la regulación de la exportación de plata en pasta fueron constantes durante la primera mitad del siglo XIX. El autor describe cómo la ley de julio de 1828 fue derogada el 9 de marzo de 1832 (Dublán y Lozano, 1876, t. II, p. 412). Posteriormente, la cronología de Lerdo (1853, pp. 44-45) apunta un momento clave en la mecánica de la exportación de plata en pasta ocurrido el 19 de enero de 1836, cuando se le concedieron al gobierno nacional facultades para otorgar permisos especiales de exportación de metales sin acuñar, una medida que respondía a una experiencia previa cuyo móvil fue detener y fiscalizar el contrabando de plata.

Tres años antes, el 17 de octubre de 1833, apareció un bando que notificaba sobre un decreto de la secretaría de Hacienda que concedía un permiso de seis meses para exportar la plata producida en los minerales de Sonora, Sinaloa, Chihuahua y Oaxaca. Para este permiso se argumentó la dificultad que representaba la conducción de los metales producidos en esos estados a la casa 
de moneda más cercana, y en caso de no otorgarse, el erario federal se exponía "a no percibir los derechos que le corresponden por el peligro de la exportación fraudulenta" (Dublán y Lozano 1876, t. II, p. 564). El gobierno nacional actuaba conforme a las circunstancias y las necesidades coyunturales. Por un lado, el permiso se concedió mediante facultades extraordinarias; por otro, respondía a las solicitudes que había hecho el representante de negocios de la corona británica en México ante las cuales, y frente a los beneficios que recibiría el erario nacional, se había otorgado dicho permiso.

Las facultades dadas al gobierno mexicano para permitir la exportación de plata en pasta en enero de 1836 reflejaron una estructura que había sido probada bajo las condiciones de la costa occidental del país. Según Lerdo (1853), estas facultades fueron usadas el 6 de junio de 1836 cuando se le concedió un permiso a la compañía del mineral de Real del Monte para la exportación de barras de plata durante un plazo de diez años. A lo largo de la primera mitad de 1837 se otorgaron varios permisos similares. El 20 de junio de ese año estos permisos fueron limitados por una ley que "reservó la gracia de exportar el oro y la plata en pasta a los puertos de Mazatlán, Guaymas y la Paz, mientras no se establecieran casas de moneda en Sonora y Sinaloa" (Lerdo, 1853, p. 45).

Fue hasta el 10 de noviembre de 1841 cuando se modificó la ley del 20 de junio de 1837, la cual establecía que los metales exportados debían pagar derechos de amonedación y exportación cual si hubiesen sido acuñados. El decreto de noviembre de 1841 argumentó que esta circunstancia representaba una sobrecarga tributaria que provocó la cuantiosa salida de metales por contrabando en detrimento de las rentas nacionales.

Investido con facultades extraordinarias en su sexto mandato al frente del país, el gobierno de Antonio López de Santa Anna estableció que el oro y la plata sin acuñar extraída por Guaymas y Mazatlán debían pagar como derecho único $7 \%$ sobre su valor, esto mientras no se establecieran casas de moneda o tesorerías de rescate. Esta tasa fue reducida a $5 \%$ el 16 de febrero de 1842 . Estas concesiones a los dos puertos del Pacífico estuvieron vigentes hasta el 5 de noviembre de 1846, fecha en la que fueron derogadas. Durante este último año habían comenzado las operaciones de la Casa de Moneda de Culiacán, situación que permitió esta abolición (Dublán y Lozano, 1876, t. Iv, pp. 47-48; Gutiérrez, 1849, p. 22; Lerdo, 1853, p. 45).

Las oscilaciones en la regulación de la exportación de plata en pasta denotan que la política comercial sirvió al gobierno mexicano para obtener recursos, hacer frente al contrabando y mediar sus relaciones con los productores mineros y los comerciantes, nacionales y extranjeros. La posibilidad de que el gobierno pudiera extender permisos a partir de enero de 1836 gana relevancia analítica si consideramos el cambio político hacia el centralismo de finales de 1835. Este viraje trasladó el control de los ingresos de las casas de moneda al gobierno central ${ }^{21}$ Esto significó que los arrendamientos pasaban a ser un asunto de la Hacienda nacional. Los permisos de exportación de plata y oro en pasta con miras a obtener recursos aduanales pusieron al gobierno mexicano en una senda de negociación con los arrendatarios de las cecas afectados por la salida de metales sin acuñar.

\footnotetext{
${ }^{21} \mathrm{Si}$ bien es cierto que el orden centralista trasladó las rentas locales al gobierno nacional, este fue un proceso complejo que implicó el reacomodo y la negociación de estas con los poderes departamentales. La constatación legal de esto fue la ley del 9 de enero de 1836 que estableció que el gobierno central sólo podía intervenir la mitad de los ingresos de los departamentos. Esta ley fue derogada por otra que fue emitida el 17 de abril de 1837 (Dublán y Lozano, 1876, t. III, pp. 117, 363).
} 
La dinámica comercial de la costa occidental, los intereses extranjeros -sobre todo británicosy la ausencia de una casa de moneda en la zona habían hecho posible mantener la liberalización en la exportación de metales en pasta por Guaymas y Mazatlán. Este último se convirtió en el motor del comercio por el Pacífico mexicano a partir de 1835. De este modo, la Casa de Moneda de Culiacán, en conjunción con las inercias que dejó la posibilidad de exportar metales sin acuñar, ejemplifica cómo se dirimieron los conflictos entre los arrendatarios de casas de moneda y el gobierno mexicano ante los permisos de exportación que este último otorgó.

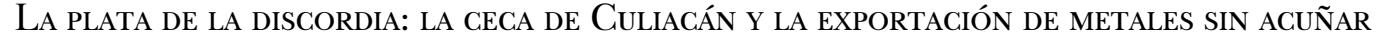

Los estados de Sonora y Sinaloa nacieron de la escisión del antiguo Estado de Occidente el 18 de octubre de 1830. Sin embargo, aunque el Congreso Constituyente de Sinaloa se instaló el 13 de marzo de 1831 (González y Ramírez, 2015, p. 27), según Román Beltrán (2003, p. 5), desde finales de 1830 las autoridades sinaloenses habían decidido abrir una casa de moneda en su territorio. El interés por poner en funcionamiento una ceca en aquella región había estado presente desde 1825, pues el gobierno del Estado de Occidente firmó un contrato con Ricardo Exter para abrir una casa de moneda en El Fuerte, en ese momento la capital occidental (Artículos, 1825, p. 2) 22

El erario sinaloense invirtió 40000 pesos para la compra de maquinaria y habilitación de la ceca de Culiacán (Gutiérrez, 1849, p. 21) y en 1834 se lanzó la primera convocatoria para que el capital privado participara mediante el arrendamiento. El 10 de enero de 1835 el gobierno estatal dio a conocer que había habilitado un local para tal fin -aunque parcialmente sin techar- y que se había instalado maquinaria, aunque la de mayor tamaño se encontraba varada en Mazatlán; en el documento se indicaba también que se buscaba una contrata con la cual pudiera completarse la construcción de la ceca y se atribuía el retraso en la apertura de la misma a unas ambiguas y "distintas causas" (Beltrán, 2003, pp. 5-6). Consideramos que una de las más relevantes fue el conflicto político al interior del estado de Sinaloa, en el que se enfrentaron las elites políticas y económicas de Cosalá con las de Culiacán. Al mismo tiempo, se fue formando durante la década de 1830 un poder fáctico propio de los comerciantes, nacionales y extranjeros, que se instalaron en Mazatlán. Los intereses de los grupos de Culiacán y Mazatlán definieron gran parte de la vida política y económica de Sinaloa. En ese escenario, la conclusión de la casa de moneda se enfrentó a la escasez de recursos estatales y a la resistencia de los comerciantes inmiscuidos en el tráfico de plata en pasta, muchos de ellos instalados en el puerto de Mazatlán (Ortega, 1999, pp. 194-199).

Fue a través del decreto del 4 de marzo de 1843 que se entregó el arrendamiento de la ceca de Culiacán a la compañía de minas de Guadalupe y Calvo, representada por José Delmonte. Tras la firma del contrato, la compañía se comprometió a empezar la acuñación en un plazo máximo

\footnotetext{
${ }^{22}$ Por otra parte, en Sonora no hubo casa de moneda hasta 1861 cuando fueron abiertas la de Hermosillo y Álamos por iniciativa del gobernador Ignacio Pesqueira. Juan Manuel Romero (2001, pp. 58-60) considera que la apertura de estas cecas debe entenderse como un acto del gobierno estatal que buscó el control y la fiscalización de los metales preciosos producidos en las minas sonorenses, pues muchos de ellos tenían como destino la Casa de Moneda de Culiacán o el contrabando. No obstante, como señala Matamala $(2008$, p. 73) estas cecas surgieron de un convenio entre el gobierno del estado y un grupo empresarial que arrendó y puso en marcha las casas de moneda. Los socios de esta compañía fueron Quintín Douglas, Guillermo Miller y Robert Symon. La apertura de las cecas en Sonora fue posible gracias al entorno político adverso el cual, a su vez, obligó en otras latitudes, como Sinaloa, el otorgamiento de permisos de exportación de plata en pasta. Una vez más, esta dicotomía complica el análisis de la relación entre casas de moneda y exportación de metales sin acuñar.
} 
de dos años, aunque este se extendió por algunos meses más, pues el registro de amonedación inició en 1846. El decreto justificaba la apertura de la ceca, argumentando que gracias a ella se evitaría la extracción "clandestina y perniciosa de plata pasta que se hace por el mismo Departamento" (Gutiérrez, 1849, p. 67). La compañía arrendataria, de capital británico, era la misma que administraba la Casa de Moneda de Guadalupe y Calvo, en Chihuahua, la cual había iniciado operaciones el 1 de junio de $1844{ }^{23} \mathrm{El}$ accionista principal en ambos negocios era el cónsul británico Ewen Mackintosh, quien entre 1847 y 1849 había logrado arrendar las casas de moneda de Guanajuato, Zacatecas, México, Guadalupe y Calvo y Culiacán, que en conjunto representaba $81.39 \%$ de la acuñación de plata y $88.57 \%$ de oro a nivel nacional (Matamala, 2008, pp. 73-74).

La compañía Manning y Mackintosh tuvo complicaciones económicas que terminaron en su debacle financiero hacia 1852 (Meyer, 2000). Fue entonces que cedió su participación en las cecas de Guadalupe y Calvo, y de Culiacán a Jecker-Torre y Compañía el 25 de agosto de 1852. El acuerdo entre los nuevos contratistas y la Hacienda nacional fue que a partir de entonces quedaba clausurada la ceca de Guadalupe y Calvo, instalándose en su lugar un fondo de rescate de plata para no perjudicar la actividad minera. Por su parte, la empresa asumió todos los compromisos establecidos en los respectivos contratos de cada una de las cecas ${ }^{24}$ Por su ubicación dentro de la sierra madre occidental, el mineral de Guadalupe y Calvo tenía más vínculos con la dinámica comercial de Sinaloa que con la de Chihuahua (véase mapa 1). En ese sentido, la consolidación de la ceca de Culiacán se tradujo en un ajuste de la estrategia productiva y de inversión de la compañía arrendataria frente a los costos que implicaba operar una casa de moneda en la región serrana y la posibilidad de exportar plata amonedada por Mazatlán, lugar de influencia de Jecker-Torre y Compañía 25

No obstante, el interés de Isidoro de la Torre en los negocios referentes a la Costa Occidental mexicana se había reducido notablemente, pues en 1854 se trasladó a la Ciudad de México desde donde operó otros giros como la adquisición de propiedades y la producción azucarera a gran escala, actividad que le redituó ganancias. En ese contexto, el 25 de noviembre de ese mismo año la empresa buscó rescindir el contrato de arrendamiento de la Casa de Moneda de Culiacán mediante un documento en donde se acordó que la casa comercial recibiría 370000 pesos de indemnización, los cuales serían saldados mediante los ingresos recibidos por la venta de La Mesilla a Estados Unidos, concretada a finales de 1853 (véase mapa 1) Esto significó la reincorporación

\footnotetext{
${ }^{23}$ Por razones de espacio no desarrollamos a profundidad el tema de la casa de moneda de Guadalupe y Calvo. No obstante, el desenvolvimiento de la ceca de Culiacán estuvo ligado a aquella de manera directa. Desde 1836, el mineral de Guadalupe y Calvo, enclavado en la sierra madre occidental, representó una apuesta del capital británico que buscó fortalecerse con la presencia de una ceca (Meyer, 1987, p. 60). Su apertura recibió el espaldarazo de Antonio López de Santa Anna quien la eximió del pago del derecho de $3 \%$ sobre metales durante cinco años (Gutiérrez, 1849, p. 30). Se mantuvo en operación hasta 1852, año en el que fue clausurada y su actividad trasladada a la ceca de Culiacán.

24 "Parte Oficial, Ministerio de Hacienda", 20 de octubre de 1852, El Siglo XIX, p. 2.

${ }^{25}$ Una fuente hemerográfica sostiene que: "la casa de moneda de Guadalupe y Calvo la tenían cerrada los contratistas [Jecker Torre y Compañía] porque les perjudicaba". "Dictamen de la comisión $1^{\text {a }}$ de Hacienda”, 3 de julio de $1856, E l$ Siglo XIX, p. 2.

${ }^{26}$ Se hace referencia a este contrato en un dictamen que realizó la primera comisión de Hacienda del Congreso constituyente el 2 de julio de 1856. "Dictamen de la comisión 1ª de Hacienda”, 3 de julio de 1856, El Siglo XIX, p. 2.
} 
momentánea de la ceca a la administración del gobierno mexicano, pues poco después, el 14 de agosto de 1855, fue arrendada de nuevo al comerciante Manuel García Granados. ${ }^{27}$ En 1855 la compañía Jecker-Torre fue disuelta (Huerta, 1981, pp. 167-170; Mayo, 2006, p. 56).

El nuevo contrato otorgado a García Granados dispuso que debía pagar por el uso de los edificios y la maquinaria la cantidad de 5000 pesos anuales durante nueve años y dar como adelanto 10000 pesos a la firma del acuerdo. Asimismo, debía entregar al erario $1 \%$ del total acuñado cada cuatro meses, una condición que apareció en muchos de los contratos de arrendamiento de casas de moneda de la época como un derecho soberano del Estado mexicano. En la cláusula 15, el gobierno se comprometió "a mantener las prohibiciones vigentes relativas a la exportación de platas pastas en el tiempo fijado en la condición duodécima [nueve años]" 28 Esta disposición fue la que le permitió a García Granados reclamar al gobierno nacional por los permisos que otorgó el gobierno de Sinaloa, el 26 de septiembre de 1855, para exportar plata pasta. Esta última fue una medida tomada por la administración estatal cuyo objetivo fue recaudar recursos que le permitieran sostener los conflictos bélicos derivados de la revolución de Ayutla.

Ante este suceso, el 26 de enero de 1856 Manuel García Granados solicitó al gobierno nacional una indemnización por la violación que había cometido Sinaloa en su contrato de arrendamiento. El contratista alegó que el gobierno sinaloense había permitido la salida de metales en pasta por la aduana de Mazatlán durante cuatro meses. Además, denunció la irrupción del comandante militar José Inguanzo a la casa de moneda, de donde extrajo 12800 pesos el 10 de noviembre de 1855 . El arrendatario aprovechó para hacer notar las malas condiciones bajo las cuales había recibido el establecimiento, situación que lo obligaba a realizar erogaciones mayores a las que tenía contempladas para su rehabilitación. Desde su perspectiva, este conjunto de condiciones había mermado la confianza de los introductores de metales y reducido el flujo de amonedación. Para indemnizarlo por todos estos daños, pidió la exoneración del pago de la renta anual y del $1 \%$ de la acuñación cuatrimestral. A cambio se comprometía a realizar las obras que necesitaba la ceca, cederle al gobierno los 10000 pesos que le había dado como adelanto de renta y renunciar a cualquier reclamo por daños derivados de los permisos de exportación de metales en pasta y de los acontecimientos violentos del 10 de noviembre de 185529

Este episodio muestra que en la Costa Occidental mexicana persistió la exportación de plata sin acuñar, a pesar de la apertura de la ceca de Culiacán en 1846. La coyuntura política y la dinámica comercial permitieron recurrir a los permisos de exportación de metales en pasta como una vía para obtener recursos fiscales ${ }^{30}$ Destaca el hecho de que el gobierno de Sinaloa fue quien hizo

\footnotetext{
${ }^{27}$ Manuel García Granados Zavala nació en 1806. Originario de Cádiz se trasladó a Guatemala en 1811 donde su padre, José García Granados, tenía negocios. Su hermano mayor, José Vicente García Granados, probó suerte en México en donde se asoció con José María Castaños para abrir una casa comercial en Mazatlán, la cual entró en operaciones hacia la segunda mitad de la década de 1830. Castaños era un comerciante cántabro que había hecho riqueza como agente comercial de Eustaquio Barrón dentro del eje San Blas-Tepic-Guadalajara. Manuel García Granados llegó a Sinaloa a través de su hermano José Vicente. Respecto a la familia García Granados, véase Zavala (1970, pp. 212-214).

${ }^{28}$ Copia del contrato de arrendamiento de la casa de moneda de Culiacán, 14 de agosto de 1855, exp. 16, fs. 50-50v, caja 7, Fondo Casa de Moneda-Fomento (en adelante famf), AGn. México.

${ }^{29}$ Solicita en nombre de Manuel García Granados, 26 de enero de 1856, viII-4. 20. 1101. 1, pp. 10-12, CRB CEHM.

${ }^{30} \mathrm{La}$ historiografía ha hecho referencia al otorgamiento de permisos de exportación en otras latitudes y los conflictos desatados por ello; por ejemplo, el 1 de noviembre de 1861 se firmó un acuerdo entre el gobierno mexicano y el arrendatario de la ceca de México, Juan Temple, en donde el primero se comprometió a pagar una indemnización de 250000 pesos por los daños causados por los permisos de exportación de plata pasta. Además, el arrendatario aceptó prestar 60000 pesos adicionales a una tasa de interés de $6 \%$ anual. El erario debía amortizar un total de 310000 pesos
} 
uso de estos recursos, lo que significó la adjudicación de una facultad en materia fiscal y comercial que estaba en manos del gobierno nacional. Por ello, el reclamo estuvo dirigido a este último y fue bajo ese panorama adverso que García Granados buscó obtener ventajas, entre ellas, dejar de transferir el flujo de renta establecido en el contrato de arrendamiento.

El 9 de mayo de 1856 la Secretaría de Hacienda respondió que era justo indemnizar al contratista por los permisos de exportación de metales en pasta, pues con ellos se incumplió el contrato de arrendamiento; sin embargo, señaló que el resto de los reclamos no tenían cabida pues el comandante José Inguanzo se había pronunciado en contra de las fuerzas políticas que le habían dado vida al gobierno en turno y este no respondería por los daños de un enemigo. Por otra parte, el erario nacional no era responsable de los malos cálculos del contratista por las reparaciones de la ceca. La indemnización debía estar en función de la cantidad de metales extraídos desde Mazatlán durante la vigencia que tuvo el decreto que lo había permitido. Para ello, era necesario tener el registro aduanal de las barras exportadas y hacer el cálculo correspondiente de lo que dejó de percibir el arrendatario ${ }^{31}$ Aunque la información disponible no permite saber si Manuel García Granados fue indemnizado, sí menciona que la salida de plata en pasta continuó después de este episodio.

El 28 de octubre de 1861 Manuel García Granados traspasó el contrato de arrendamiento de la Casa de Moneda de Culiacán a Fortunato de la Vega, convenio que quedó protocolizado el 3 de febrero de $1862{ }^{32}$ El trato fue que el antiguo contratista recibiría 15000 pesos en libranzas que serían aceptadas por Antonio de la Vega y Rábago, padre del nuevo contratista ${ }^{33}$ De este modo, la casa de moneda pasó al control directo de una familia importante de Culiacán. ${ }^{34}$ Dos meses después, el 8 de abril de 1862, Fortunato de la Vega solicitó al gobierno mexicano una indemnización por el incumplimiento de la condición 15 del contrato de arrendamiento que se le había traspasado. Según el nuevo arrendatario, los conflictos políticos obligaron a los gobiernos de Sonora, Chihuahua y Sinaloa a conceder permisos para el embarque de plata en pasta con el fin de recaudar recursos desde 1859. La adjudicación de facultades fiscales y comerciales del gobierno nacional por parte de los estados se hacía presente. La situación había afectado los intereses del arrendatario y por esta razón pedía una indemnización de 150000 pesos, cantidad que debía ser amortizada con la renta generada por el arrendamiento, el producto de los derechos de amoneda-

al contratista. A pesar de este acuerdo, el gobierno volvió a dar permisos de exportación en diciembre de 1861 ante las necesidades fiscales derivadas de la complicada situación política. Ya en julio de ese año se había declarado la suspensión del servicio de la deuda que sirvió de pretexto para la intervención francesa. Esta situación fue expuesta por el albacea de Juan Temple, José Antonio de Mendizábal, en 1868 como parte de una exposición dirigida al gobierno mexicano para pedir el cumplimiento del contrato y el pago pendiente de las indemnizaciones (Mendizábal, 1868, pp. 27-29).

${ }^{31}$ Solicita en nombre de Manuel García Granados, 9 de mayo de 1856, VIII-4. 20.1101.1, p. 13, CRB, CEHM.

${ }^{32}$ Testimonio de la escritura sobre contrato de la Casa de Moneda de Culiacán habido entre los señores don Fortunato de la Vega y don Manuel García Granados, exp. 16, fs. 5-9, caja 7, FGMF, AGN, México.

${ }^{33}$ Copia del contrato de arrendamiento de la Casa de Moneda de Culiacán, 14 de agosto de 1855, exp. 16, f. 51v, caja 7, FCMF, AGN, México.

${ }^{34}$ Antonio de la Vega y Rábago pertenecía a una familia influyente de Culiacán. Su hermano Manuel María de la Vega y Rábago gobernó Sinaloa de enero a octubre de 1835, mientras que Rafael de la Vega y Rábago ocupó la gubernatura cuatro veces entre 1845 y 1847. El grupo político de Vega rivalizó económicamente con los grupos de comerciantes extranjeros de Mazatlán, controlando el flujo comercial del norte y el centro de Sinaloa, así como contrabandeando por el puerto de Altata. La historiografía coincide en que el predominio político de la familia terminó en 1853 con el derrocamiento de otro gobernador miembro de la estirpe: Francisco de la Vega y Rábago. Fortunato de la Vega pertenecía a este clan que mantuvo sus actividades comerciales a pesar de su desplazamiento en la palestra política (González y Ramírez, 2015, pp. 27-38; Ortega, 1999, pp. 192-196, 207-210). 
ción, los derechos de minería y los del quinto recaudados en la casa de moneda. Los abonos del pago debían ser registrados en una cuenta controlada por el interventor del gobierno mexicano en la ceca de Culiacán 35

En el momento de este reclamo faltaban dos años para que el contrato firmado en 1855 llegara a su fin, por ello, Fortunato de la Vega aprovechó la circunstancia y solicitó, como parte de la indemnización, una prórroga de diez años. Las proposiciones fueron aceptadas por el gobierno en turno el 25 de abril de 1862 pero la indemnización estaba lejos de ser saldada. Manuel García Granados reclamó que la compensación concedida a Fortunato de la Vega en realidad le correspondía a él, puesto que la exportación de metales ocurrió cuando la ceca estaba bajo su administración. Agregó que la casa comercial de Vega había sido una de las beneficiadas con la exportación de plata en pasta y señaló: “¿Será justo que el gobierno indemnice al señor Vega por los daños que su misma casa ocasionó con las exportaciones de platas?"36 Esto fue el inicio de una disputa que el gobierno aprovechó para prolongar el pago de la indemnización y en el mediano plazo recuperar el control de la Casa de Moneda de Culiacán.

Ante el reclamo de García Granados, el 22 de noviembre de 1863 la secretaría de Hacienda ordenó dejar sin efectos el arreglo que tenía con Vega, tanto en lo concerniente a la prórroga como al abono de 150000 pesos. Sin embargo, el 2 de diciembre de 1863 se le comunicó a la jefatura de Hacienda de Sinaloa que la disposición del 22 de noviembre quedaba derogada en todas sus partes. La indemnización iba a liquidarse siempre y cuando el arrendatario comprobara la salida de plata en pasta y entregara "la refacción de un crédito por 20000 pesos" 37 Esto fue ratificado desde Saltillo por el ministro José María Iglesias el 28 de enero de 1864, quien ordenó respetar el acuerdo con Fortunato de la Vega. El gobierno mexicano aprovechaba la disputa para obtener liquidez, sobre todo en un contexto político marcado por la confrontación entre el grupo liberal republicano y la presencia del Segundo Imperio mexicano.

El contexto político nacional provocó que en cuatro años no hubiera noticia alguna sobre la indemnización. Tras la reinstauración de la República, un acuerdo del 30 de marzo de 1868 declaró vigente la orden del 22 de noviembre de 1863, es decir, aquella que desconoció la indemnización y la prórroga a Fortunato de la Vega. El 4 de junio de 1868 el director de la ceca sinaloense, Guillermo Mackintosh, denunció que la casa de moneda había sido intervenida y que el asunto parecía una persecución política de la jefatura de Hacienda en Sinaloa hacia Fortunato de la Vega, en vez de un aseguramiento judicial. Desde la perspectiva de Mackintosh, el asunto ya había sido resuelto y lo excepcional de la situación se explicaba por el retraso en la liquidación de la indemnización, asunto que el contratista trató de resolver sin éxito 38 Dentro de esta coyuntura resalta que el contratista se vería obligado a justificar las partidas de la indemnización; que el gobierno mexicano no había liquidado por completo la indemnización, pero sí había transferido recursos al arrendatario por ese concepto, y que las sospechas de persecución a la casa comercial de Fortunato de la Vega eran indicios de que el gobierno buscaba rescindir el contrato de arrendamiento.

Para sostener su indemnización, Fortunato de la Vega presentó documentos aduanales que mostraban la salida de metales en pasta entre noviembre de 1859 y diciembre de 1863 por el puerto de Mazatlán. Con base en esto, el contratista aumentó el monto de sus reclamaciones a

${ }^{35}$ El C. Fortunato de la Vega ha presentado al Supremo Gobierno la proposición que consta, 8 de abril de 1862, exp. 16, fs. 55-56, caja 7, FGMF, AGN, México.

${ }^{36}$ Manuel G. Granados ante usted en la debida forma expongo, sin fecha, exp. 16, f. 2, caja 7, FGMF, AGN. México.

${ }^{37}$ Números 2 y 3, 2 de diciembre de 1863, exp. 16, fs. 10-12v, caja 7, FGMF, AGN, México.

${ }^{38}$ Ciudadano presidente, 4 de junio de 1868, exp. 16, fs. 22-26v, caja 7, FCMF, AGN, México. 
165642 pesos, un incremento producto de la salida de 136197 marcos de plata de los cuales 54198 pertenecían al mineral de Cosalá. Según Vega, los metales de este mineral, en especial los de mina de Guadalupe de los Reyes, eran de alta ley en plata y oro, lo que incrementaba el valor de la indemnización (véase mapa 1). Además, otra de las pruebas presentadas por Vega fue un permiso otorgado a Francisco G. Palacio para exportar por el puerto de Mazatlán hasta 10000 marcos de plata procedentes de Durango. Miguel Bustamante, funcionario de la Secretaría de Fomento, argumentó que, si se habían dado permisos para exportar plata de otros estados, no había certeza de que los 136197 marcos exportados pertenecieran por completo a Sinaloa, ni mucho menos al mineral de Cosalá, lo que sirvió para objetar el incremento solicitado; este episodio muestra cómo el gobierno mexicano buscó contener los intereses del arrendatario 39

La política del gobierno mexicano dirigida al impulso de la minería vio en la cancelación de los arrendamientos de las cecas una condición que facilitaría la exportación de plata en pasta, situación que beneficiaría a los productores mineros, un objetivo cuyo principal artífice fue Matías Romero ${ }^{40}$ Tras el conflicto desatado por la orden del 30 de marzo de 1868 -que desconoció la indemnización- se suspendió la transferencia de los recursos generados en la ceca que eran propiedad del erario y que estaban destinados a cubrir la indemnización. A partir del 1 de junio de 1868 la cuenta que recibía estos ingresos dejó de hacerlo ${ }^{41}$ Los datos disponibles indican que entre 1863 y el 2 de junio de 1868 el gobierno había abonado 147565 pesos ${ }^{42}$ La indemnización solicitada por Vega estaba casi liquidada, lo que ampliaba el margen de negociación del gobierno nacional para lograr una posible recisión del contrato. A la luz de esto, la intervención judicial que hizo el gobierno al establecimiento en marzo de 1868 era un indicio de que se buscaba la reincorporación de la ceca a la administración pública. Se trataba de una casa de moneda ubicada en una zona donde la exportación de metales en pasta había persistido, lo que costaba al erario recursos por la vía de las indemnizaciones.

\footnotetext{
${ }^{39}$ Dictamen de Miguel Bustamante, 12 de agosto de 1868 en “Ciudadano Ministro”, exp. 16, fs. 94-95v, caja 7, FCMF, AGN, México. A partir de junio de 1868 las casas de moneda dejaron de ser parte de la secretaría de Hacienda y pasaron a la de Fomento. La lógica era que dejaran de ser instrumentos para procurar recursos financieros y que se convirtieran en verdaderos nodos del fomento minero, una perspectiva que había sido planteada por el titular de Hacienda Matías Romero. Véase Calderón (1955, p. 166).

${ }^{40}$ Matías Romero estuvo en el cargo de secretario de Hacienda del 16 de enero al 25 de mayo de 1868; luego del 8 de agosto al 20 de noviembre de 1868; del 30 de septiembre de 1869 al 12 de junio de 1872; del 24 de mayo de 1877 al 4 de abril de 1879 y del 1 de enero de 1892 al 7 de mayo de 1893. En la memoria de Hacienda de 1870 suscribe: "El ejecutivo da tanta mayor importancia a la cuestión de conceder franquicias a la minería, cuanto que la considera como una de las maneras más eficaces de dar una solución conveniente a la cuestión del deficiente... impulsando el movimiento mercantil, a fin de que sea mayor el producto de los impuestos existentes sin aumentar las cuotas de estos... Las franquicias de exportar los metales preciosos en pasta, es pues la primera y más urgente necesidad para el desarrollo de la industria minera”. Citado en Yáñez (1958, t. II, pp. 182-183). Respecto al proceso, políticas, condiciones y alcances de la recuperación de las casas de moneda por parte del gobierno mexicano durante el último cuarto del siglo XIX, véase Herrera (1999, pp. 25-29).

${ }^{41}$ Recordemos que se destinó la renta de la ceca, el producto de los derechos de amonedación, los derechos de minería y los de quinto recaudados en el establecimiento para ser abonados a la indemnización de Fortunato de la Vega. Registrado en El c. Fortunato de la Vega ha presentado al Supremo Gobierno la proposición que consta, 8 de abril de 1862, exp. 16, fs. 55-56, caja 7, FGMF, AGN, México.

${ }^{42}$ Los datos pormenorizados muestran que el contratista nunca pagó la renta del edificio, pues ese rubro se abonó completo al pago de la indemnización. En Cantidades que tiene recibidas don Fortunato de la Vega, 22 de septiembre de 1868, exp. 16, f. 98, caja 7, FGMF, AGN, México.
} 
A partir de la segunda mitad de 1868 se planteó revocar el arrendamiento de la Casa de Moneda de Culiacán. Durante 1869 las negociaciones entre el gobierno mexicano y los representantes de Fortunato de la Vega tuvieron avances. El objetivo de ambas partes era que la ceca fuera entregada a finales de ese año, pero el acuerdo no se concretó por desavenencias económicas. Si bien habían dejado de transferirse recursos del erario al contratista desde junio de 1868, estos continuaron depositándose a modo de reserva mientras se resolvía la situación. Un año después -y en medio del proceso de negociación- el depósito había alcanzado un monto de 21763 pesos 43 Estos recursos fueron los que sirvieron como sustento para lograr la cancelación del arrendamiento. El 26 de marzo de 1870 se acordó que el gobierno cancelaría todas las cuentas pendientes del contratista y le entregaría 20000 pesos del depósito para anular el acuerdo contractual. La entrega debía darse el 30 de junio de ese año ${ }^{44}$ El 5 de julio de 1870 Fortunato de la Vega se dirigió al gobierno para dar los pormenores de la recepción de la ceca por parte del gobierno nacional ${ }^{45}$

Este episodio muestra cómo el tránsito constante de la plata pasta por los puertos del occidente del país, en coexistencia con una casa de moneda bajo arrendamiento, generó conflictos entre el contratista y el gobierno mexicano. La exigencia del pago de indemnizaciones fue un punto de discordia que se tradujo en una merma de recursos para el erario nacional. El control del gobierno sobre una ceca como la de Culiacán significaba la posibilidad de administrar los permisos de exportación de metales a favor del erario y de la minería sin el inconveniente de lidiar con reclamos por parte de los arrendatarios. Esta fue la apuesta del gobierno y de la Hacienda pública a partir de 1868 en materia de casas de moneda, pues, entre 1868 y 1871, fueron recuperadas cinco de las once cecas arrendadas: Guadalajara, Durango, Álamos, Hermosillo y Culiacán.

No obstante, como sustenta Inés Herrera (1999, pp. 24-25), este primer paso en el proceso de reincorporación de las cecas fue efímero. El 29 de agosto de 1876 fueron arrendadas a Roberto Symon y Compañía las casas de moneda de Culiacán, Álamos y Hermosillo. Juan Fernando Matamala (2008, pp. 78-79) explica cómo las presiones presupuestales que generó la revuelta de Tuxtepec a inicios de 1876 orillaron al gobierno de Sebastián Lerdo de Tejada al arrendamiento de seis casas de moneda en menos de un año y a prorrogar el contrato de la ceca capitalina. Tras este episodio, el contrato de arrendamiento de la ceca de Culiacán fue prorrogado tres veces: el 20 de diciembre de 1879 , el 1 de junio de 1883 y el 4 de febrero de 1888 . Fue hasta finales de 1892 que se perfiló el fin del esquema de contratas en las cecas del país. El 19 de diciembre de ese año un decreto impulsado por Matías Romero autorizó al gobierno a gestionar la rescisión de los arrendamientos mediante la negociación del pago de los adeudos que tenía el erario nacional con los contratistas (Beltrán, 2003, pp. 25-26). Bajo este esquema, el 25 de enero de 1896 se le informó a la compañía arrendataria de las cecas de Hermosillo, Álamos y Culiacán que se le adeudaban 38000 pesos, monto que fue aceptado y pagado un mes después. Este hecho significó el fin del arrendamiento en Culiacán y también la clausura de las cecas de Hermosillo y Álamos.

La relevancia de la Casa de Moneda de Culiacán como centro de amonedación estuvo ligada a la dinámica comercial del occidente del país; muestra de ello fue que hacia 1900, cuando habían sido clausuradas la mayor parte de las cecas, esta seguía en funcionamiento junto con la de Ciudad de México y Zacatecas. El cierre definitivo del establecimiento de amonedación sinaloense se dio en 1905 como parte de una de las condiciones de la reforma monetaria de ese año. El proceso

\footnotetext{
${ }^{43}$ Intervención de la Casa De Moneda de Culiacán, 7 de septiembre de 1869, exp. 16, fs. 136-137, caja 7, FCMF, AGN, México.

${ }^{44}$ C. Ministro de Fomento, 26 de marzo de 1870, exp. 16, fs. 144-146, caja 7, FCMF, AGN, México.

${ }^{45}$ Me fue comunicada, 5 de julio de 1870, exp. 16, f.163, caja 7, FCMF, AGN, México.
} 
de reincorporación de las cecas y la clausura de estas, esbozado en estas últimas líneas, es una importante veta que debe ampliarse en futuras investigaciones. Su exploración daría cuenta de cambios estructurales en el ámbito fiscal, monetario, minero y comercial de México y el mundo de finales del siglo xIx y principios del xx.

\section{Conclusión}

La guerra de independencia transformó el escenario económico novohispano. Las disrupciones heredadas por el México independiente se manifestaron en dos ejes de la actividad económica: el comercio y la acuñación. La intensificación del comercio por la Costa Occidental mexicana y la posibilidad de extraer metales a través del contrabando colocó a esta zona del país como un punto clave del comercio a escala internacional. En ese sentido, la regulación de la exportación de plata en pasta, que permitió la salida legal de este tipo de metales por los puertos de Guaymas y Mazatlán hasta 1846, fue posible debido a que no funcionaba una casa de moneda cercana a los minerales de la zona. La posibilidad de extraer plata sin acuñar mediante el pago de un derecho de exportación le permitió al erario nacional fiscalizar este recurso y contener un poco la vía del contrabando.

La guerra de independencia hizo posible la apertura de otras casas de moneda además de la ubicada en Ciudad de México, y pese a que se buscó su clausura hacia 1815; cecas como la de Zacatecas y Guadalajara lograron el reconocimiento oficial en 1821. La llegada del orden federal y la repartición de rentas de agosto de 1824 dejó en manos de los estados los ingresos generados por las casas de moneda estatales. Esto provocó el interés de las entidades federativas con recursos mineros por abrir establecimientos de acuñación. De esta forma, algunos gobiernos estatales vieron en el arrendamiento a particulares un camino para gestionar y poner en marcha su casa de moneda. Esta situación dio pie a un punto de tensión: la salida de metales sin acuñar a través de la cual el gobierno nacional obtenía ingresos aduanales se contraponía a los intereses de los gobiernos estatales y de los contratistas.

El viraje hacia el centralismo, entre 1835 y 1836, le permitió al gobierno nacional inmiscuirse en asuntos vinculados con los ingresos generados por las casas de moneda de los entonces departamentos. Un punto clave fue la posibilidad de intervenir en los contratos de arrendamiento de las cecas. En ese contexto, en enero de 1836 se le otorgaron al gobierno central facultades para conceder permisos especiales de exportación de oro y plata sin acuñar. Estos dos elementos generaron un escenario en el que la secretaría de Hacienda tuvo márgenes para negociar sobre la salida de metales en pasta con quienes tenían intereses en la minería, el comercio y el proceso de acuñación. Esta situación se dio de modo particular en la Casa de Moneda de Culiacán, un establecimiento ubicado en una zona en donde el tráfico y contrabando de estos metales había sido clave en la expansión comercial de la Costa Occidental mexicana y específicamente de Mazatlán.

La ceca sinaloense comenzó operaciones en 1846, mismo año en que se prohibió la extracción de plata no amonedada por los puertos de Guaymas y Mazatlán. A pesar de esta restricción, la inercia exportadora, el contexto político y la necesidad de recursos fiscales obligaron al gobierno estatal a otorgar permisos de exportación de plata en pasta. Esta medida incumplió la cláusula 15 del convenio de arrendamiento que le garantizaba al contratista que no saldrían metales sin haber

sido acuñados. Este suceso muestra la apropiación de facultades fiscales y comerciales del gobierno nacional por parte de los estados, de ahí la complejidad del escenario político y económico del país, así como de la desarticulación institucional que enfrentó el Estado mexicano durante la primera 
mitad del siglo xix. A pesar de ello, destaca el hecho de que la disputa por la indemnización que debía pagarse al arrendatario, así como el mecanismo del que echó mano el gobierno nacional para saldarla, sirvieron para negociar la rescisión del contrato. Se trataba de una medida que corría a la par de una política nacional cuyo objetivo era recuperar las casas de moneda y hacer posible la exportación de metales sin acuñar a nivel nacional (Herrera, 1999, pp. 25-27).

Detrás de esta serie de negociaciones y de estrategias, el gobierno mexicano recuperó la administración de la ceca de Culiacán el 30 de junio de 1870. Si observamos este caso en relación con su contexto, podemos sostener que los procesos de apertura, alquiler y recuperación de esta casa de moneda permiten identificar uno de los primeros intentos por darle un giro a la política económica en relación con los establecimientos de acuñación arrendados. No fue casual que el 24 de diciembre de 1871 se promulgara una ley que autorizó la exportación de plata en pasta bajo la condición de que pagara los derechos de amonedación. El propósito era que estos recursos fueran entregados a los arrendatarios, de esta forma no se transgredían los compromisos adquiridos en los contratos y la minería se beneficiaba en dos sentidos: primero, se reducía el costo de transportar los metales hasta las casas de moneda; segundo, el beneficio de metales con bajas leyes resultaba rentable. Al mismo tiempo se esperaba que los ingresos fiscales por la vía de los derechos de exportación crecieran puesto que aumentaba la base gravable (Calderón, 1955, pp. 169-170).

La posibilidad de exportar plata en pasta bajo los términos de la ley del 24 de diciembre de 1871 se vio favorecida cuando el gobierno mexicano logró hacia 1870 la recuperación de las casas de moneda de Guadalajara, Durango, Álamos, Hermosillo y Culiacán, así como en 1874 se adjudicó las de Guanajuato, Zacatecas, San Luís Potosí, Chihuahua y Oaxaca. En cambio, la ceca de Ciudad de México quedó bajo la administración privada. Sin embargo, no fue una política sostenible en el mediano plazo, pues el erario nacional tuvo que echar mano de los arrendamientos para sacar a flote los gastos derivados de la revuelta de Tuxtepec. En menos de un año, el gobierno de Sebastián Lerdo de Tejada arrendó seis casas de moneda, entre ellas, la de Culiacán en agosto de 1876. Recibió a cambio 20000 pesos de renta y un préstamo de 35000 pesos (Matamala, 2008, p. 83). Las condiciones de estos últimos arrendamientos, las dinámicas particulares de los mismos y el proceso de recuperación de las cecas hacia finales del siglo XIX son temas para futuras investigaciones.

\section{LISTA DE REFERENCIAS}

Beltrán, R. (2003). La Casa de Moneda de Culiacán. Documenta Culiacanense, 5, 3-32.

Bernecker, W. L. (1992). De agiotistas y empresarios: En torno de la temprana industrialización mexicana (siglo XIX) (P. Chinchilla, trad.). México: Universidad Iberoamericana.

Bonialian, M. y Hausberger, B. (2018). Consideraciones sobre el comercio y el papel de la plata hispanoamericana en la temprana globalización, siglos XVI-XIX. Historia Mexicana, 68(1), 197 244. DOI: $10.24201 / \mathrm{hm} . v 68 \mathrm{i} 1.3641$

Busto, K. (2008). El espacio del Pacífico mexicano: Puertos, rutas, navegación y redes comerciales, 18481927 (Tesis de doctorado). El Colegio de México, México.

Calderón, F. (1955). La vida económica. En D. Cosío (ed.), Historia moderna de México. La república restaurada (pp. 115-185). México: Hermes.

Contreras, J. M. (2017). La inversión privada en la comarca tepiqueña, 1821-1871. México: Universidad Nacional Autónoma de México.

Dublán, M. y Lozano, J. M. (1876). Legislación mexicana. México: Imprenta del Comercio. 
Estep, R. (2010). Exter, Richard. Recuperado dehttps://tshaonline.org/handbook/online/articles/ fex03

Gutiérrez, B. (1849). Memoria presentada a la Cámara de Diputados sobre la creación y estado actual de las casas de moneda. México: Tipografía de M. Murguía.

Herrera, I. (1977). El comercio exterior de México, 1821-1875. México: El Colegio de México.

Herrera, I. (1988a). Comercio y comerciantes de la Costa del Pacífico mexicano a mediados del siglo XIx. Historias, 20, 129-135.

Herrera, I. (1988b). En busca del Nuevo Almadén. Archivos, libros y revistas en los acervos californianos. Historias, 20, 159-178.

Herrera, I. (1999). El rescate de las casas de moneda: Un paso a la concentración de las rentas federales a finales del siglo xix. El Mercado de Valores, 59(11), 20-29.

Huerta, M. T. (1981). Isidoro de la Torre: El caso de un empresario azucarero. 1844-1881. En C. F. Cardoso (ed.), Formación y desarrollo de la burguesía en México siglo XIX (pp. 164-187). México: Siglo Veintiuno Editores.

Huerta, M. T. (1993). Empresarios del azúcar en el siglo XIX. México: Instituto Nacional de Antropología e Historia.

Ibarra, A. (1998). El comercio y el poder en México, 1821-1864: la lucha por las fuentes financieras entre el Estado central y las regiones. México: Fondo de cultura económica/Universidad de Guadalajara.

Lerdo, M. (1853). Comercio exterior de México, desde la conquista hasta hoy. México: Rafael Rafael.

Martínez, E. (2012). La Casa de Moneda de Zacatecas durante la primera República Federal. Berlín: Académica Española.

Martínez, G. (2015). Negocios, política y diplomacia en México. El caso del cónsul Ewen Clark Mackintosh, 1827-1852. En M. Palacios (ed.), Negocios, empresarios y entornos políticos en México, 1827-1958 (pp. 21-56). México: El Colegio de México.

Matamala, J. F. (1996). La Casa de Moneda de Zacatecas, 1876-1895. Un caso de empresa regional (Tesis de licenciatura). Escuela Nacional de Antropología e Historia, México.

Matamala, J. F. (2008). Las casas de moneda foráneas, 1810-1905. Historias, 71, 61-85.

Mayo, J. (2006). Commerce and contraband on Mexico's West Coast in the era of Barron, Forbes \& Co., 1821-1859. Nueva York: Peter Lang.

Mendizábal, J. A. (1868). Exposición que José Antonio de Mendizábal, albacea de don Juan Temple, dirige al gobierno mexicano pidiéndole el cumplimiento del contrato de 28 de junio de 1856. México: Díaz de León y White Impresores.

Mentz, B. (ed.). (1982). La relación hombre-naturaleza: Reflexiones desde distintas perspectivas disciplinarias. México: Centro de Investigaciones y Estudios Superiores en Antropología Social.

Meyer, R. M. (1987). Los ingleses en México, la casa Manning y Mackintosh (1824-1852). Historias, 16, 57-72.

Meyer, R. M. (2000). La quiebra de la firma Manning y Mackintosh. En G. Altamirano (ed.), Prestigio, riqueza y poder: Las elites en México, 1821-1940 (pp. 87-114). México: Instituto de Investigaciones Dr. José María Luis Mora.

Ortega, S. (1999). Breve historia de Sinaloa. México: Colegio de México/Fondo de Cultura Económica. 
Parra, A. (1998). Control estatal vs. Control privado: La Casa de Moneda de Guanajuato en el siglo xix. En J. A. Bátiz-Vázquez y J. E. Covarrubias (eds.), La moneda en México, 1750-1920 (pp. 155-168). México: Instituto de Investigaciones Dr. José María Luis Mora/El Colegio de Michoacán.

Parra, A. (2014). Elementos locales y extranjeros en la configuración tecnológica de la minería mexicana. Istor, 14(56), 141-163.

Román, R. A. (1998). El comercio en Sinaloa, siglo XIX. México: Consejo Nacional para la Cultura y las Artes.

Romero, J. M. (2001). La minería en el noroeste de México: Utopía y realidad, 1850-1910. México: Universidad de Sonora/Plaza y Valdés Editores.

Sanabria, J. N. (1830). Análisis y observaciones al artículo editorial sobre casas de moneda, del correo de la federación mejicana de 9 de mayo de 1830. Por el ciudadano Juan Nepomuceno Sanabria ensayador y juez de balanza por la federación en la Casa de Moneda de S. Luis Potosí. San Luis Potosí: Imprenta del Estado.

Sánchez, E. (2016). La imperiosa necesidad: Crisis y colapso del erario de Nueva España (1808-1821). México: Instituto de Investigaciones Dr. José María Luis Mora/El Colegio de Michoacán.

Sánchez, M. G. (2003). Las vicisitudes monetarias de los tapatíos: La ceca de Guadalajara, 1811-1895. México: Secretaria de Cultura Jalisco.

Tardiff, G. (1968). Historia general del comercio exterior mexicano: antecedentes, documentos, glosas y comentarios, 1503-1847, t. I. México: Gráfica Panamericana.

Velasco, C. (1994). Casas de moneda en México, 1821-1871. En I. González (ed.), Minería americana colonial y del siglo XIX. México: Instituto Nacional de Antropología e Historia.

Velasco, O. (2016). Política, ingresos y negociación: el arrendamiento de las casas de moneda de Guanajuato, Zacatecas y la ciudad de México frente a la construcción de la Hacienda pública nacional, 1825-1857 (Tesis de doctorado). Instituto de Investigaciones Dr. José María Luis Mora, México.

Yáñez, M. (1958). El problema fiscal en las distintas etapas de nuestra organización política, t. II. México: Talleres de Impresión de Estampillas y Valores.

Zavala, J. (1970). Miguel García Granados y Zavala, presidente de Guatemala. Revista Conservadora del Pensamiento Centroamericano, 112, 190-216.

Hemerografía

El Siglo XIX, Ciudad de México, México.

Archivos

Agn Archivo General de la Nación, Ciudad de México, México.

сенм Centro de Estudios de Historia de México Carso, Ciudad de México, México. 